\title{
Optimizing performance through intrinsic motivation and attention for learning: The OPTIMAL theory of motor learning
}

\author{
Gabriele Wulf $^{1} \cdot$ Rebecca Lewthwaite ${ }^{2,3}$
}

Published online: 29 January 2016

(C) Psychonomic Society, Inc. 2016

\begin{abstract}
Effective motor performance is important for surviving and thriving, and skilled movement is critical in many activities. Much theorizing over the past few decades has focused on how certain practice conditions affect the processing of task-related information to affect learning. Yet, existing theoretical perspectives do not accommodate significant recent lines of evidence demonstrating motivational and attentional effects on performance and learning. These include research on (a) conditions that enhance expectancies for future performance, (b) variables that influence learners' autonomy, and (c) an external focus of attention on the intended movement effect. We propose the OPTIMAL (Optimizing Performance through Intrinsic Motivation and Attention for Learning) theory of motor learning. We suggest that motivational and attentional factors contribute to performance and learning by strengthening the coupling of goals to actions. We provide explanations for the performance and learning advantages of these variables on psychological and neuroscientific grounds. We describe a plausible mechanism for expectancy effects rooted in responses of dopamine to the anticipation of positive experience and temporally associated with skill practice. Learner autonomy acts perhaps largely through an enhanced expectancy pathway. Furthermore, we consider
\end{abstract}

Gabriele Wulf and Rebecca Lewthwaite contributed equally to this work.

Gabriele Wulf

gabriele.wulf@unlv.edu

1 Department of Kinesiology and Nutrition Sciences, University of Nevada, Las Vegas, NV 89154-3034, USA

2 Rancho Los Amigos National Rehabilitation Center, Downey, CA, USA

3 University of Southern California, Los Angeles, CA, USA the influence of an external focus for the establishment of efficient functional connections across brain networks that subserve skilled movement. We speculate that enhanced expectancies and an external focus propel performers' cognitive and motor systems in productive "forward" directions and prevent "backsliding" into self- and non-task focused states. Expected success presumably breeds further success and helps consolidate memories. We discuss practical implications and future research directions.

Keywords Motivation · Attentional focus · Self-efficacy · Positive affect $\cdot$ Dopamine $\cdot$ Motor performance

Skilled movement is fundamental to surviving and thriving in the world and the basis as well for many of the highest human endeavors and cultural achievements, from sport to art to music. How people learn and relearn movement skills has been addressed from a number of disparate scientific perspectives and levels of analysis, including behavioral, social cognitive, neurophysiological, and neurocomputational. In part, differences in assumptions, scientific terminology and philosophy, as well as methodological approaches have made scholarly rapprochement challenging, but we see the end goal of optimizing motor learning as important. We suggest that it may be valuable to bring recent insights from various approaches together to identify a coherent way forward that can result in optimized learning from humans' earliest encounters with new motor skills to the lifelong development of motoric expertise.

It is typically considered time to look afresh at dominant theories in a field when the accumulating evidence suggests that old frameworks cannot account for substantial new insights and data. We contend that such a circumstance exists with respect to the state of motor learning theory. With respect to the need to refresh and align perspectives on motor learning 
theories, we posit that a substantial body of knowledge has accumulated with respect to behavioral evidence on intrinsic forms of motivational influences as well as the focus of movers' attention and its effects on motor performance and learning. None of these literatures has a home within prevailing theoretical approaches, yet they have had substantial play within the empirical realm. Where and how might they (and other related research) fit our conceptions of important influences on human motor performance and learning? Furthermore, there have been continuing advances beyond origins in animal models in neuroscience, including content related to human social, cognitive, affective, and motor neuroscience. These advances include insights into brain structure and function, network connectivity, neuromodulators of brain activity, mechanisms of neuroplasticity, and in methodology (Braver, Krug, Chiew, Kool, Westbrook, Clement et al., 2014). Moreover, beyond its connections to neuroscience, psychological science (and sport psychology) provide important experimental, observational, and qualitative perspectives on especially longer-term influences on skilled motor behavior that should inform theories that purport to explain realworld and sustainable motor learning. With such an expansion of available insights, we think it is time to begin to explore a richer blend of findings from these different scholarly traditions to contribute to our ability to influence movement learning in the many domains of human endeavor where it is crucial or desirable. The collective lines of behavioral research can provide perspectives on influences and mechanisms of human motor performance and learning beyond what can easily be accomplished in a neuroimaging scanner, heightening insights into the ecological validity of that work. Furthermore, the breadth of experimental manipulations regarding positive motivational influences on learning may suggest ways to expand upon the heavy use of extrinsic rewards in studying neural systems with roles in learning. That being said, we note that our anchoring perspective is in human motor behavior per se, as it can be studied experimentally with classical phases of skill acquisition and learning in the forms of retention and transfer tests for motor skill.

\section{Need for a new perspective}

While the popularity of various factors or practice conditions that affect motor learning (e.g., variable versus constant practice, random versus blocked practice, augmented feedback, movement observation, self-controlled practice) has changed over the years, what has been fairly consistent across different lines of research is the interpretation of how these factors affect learning. Stemming from earlier models of humans as computer-like processors of information (Broadbent, 1958; Sternberg, 1969), factors influencing motor learning have been viewed almost invariably from a motivationally neutral information-processing perspective. The view that motor learning is enhanced by practice conditions that make information processing more difficult and effortful has dominated the discourse in the motor learning literature (Guadagnoli \& Lee, 2004; Lee, Swinnen, \& Serrien, 1994; Schmidt \& Bjork, 1992). While the task-related informational functions of augmented feedback, model presentations, or variable or random practice, etc. are likely important, it has become clear that motivational (e.g., social-cognitive, affective) factors associated with various practice conditions have an important influence on learning as well (Lewthwaite \& Wulf, 2010a, 2012). Theoretical perspectives (Salmoni, Schmidt, \& Walter, 1984; Schmidt, 1975) that consider no more than temporary motivational influences are not able to capture and adequately explain the entirety of influences on motor behavior, including perhaps some of the most important ones.

Given the considerable advances in our understanding of motor skill learning over the past few decades, a new theory that encompasses new findings - some of which are the result of new methodologies - is needed. Therefore, in the present paper, we propose a theory of motor learning that takes into account the social-cognitive-affective-motor nature of "motor" behavior (Lewthwaite \& Wulf, 2010a): The OPTIMAL (Optimizing Performance Through Intrinsic Motivation and Attention for Learning) Theory. Before outlining this new theory, we discuss the intertwined nature of motor, cognitive, affective, and sociocultural influences on performance. We then review findings that point to strong motivational and attentional focus impacts on motor learning. Next, we describe the OPTIMAL theory, which takes into account those new insights, as a new perspective on motor learning. The foundation of our theory is motor behavior. That is, we are less concerned with skills that have a strong cognitive or decision-making component (i.e., learning "what"; see Shmuelof \& Krakauer, 2011). Rather, of concern is primarily the learning of "how" to bring about the coordinated or skilled control of (complex) movement, for which the quality of movement execution is of primary importance (Shmuelof \& Krakauer, 2011). Certainly, the acquisition of skilled movement would allow for more effective integration with strategic and interactive decisions relevant to natural contexts of motoric achievement.

\section{Social-cognitive-affective-motor behavior}

Human behavior, including motor behavior, is embedded in a cultural context, with norms and stereotypes about appropriate or expected activities for certain age, gender, or ethnic groups (Stone, Lynch, Sjomeling, \& Darley, 1999). Motor behavior is observable and often performed publicly, that is, in a social context. The presence of another person, or other persons, may provide reassurance (e.g., rehabilitation 
alongside another person who has experienced a stroke) or conjure pressure to perform well, and exert facilitating or impeding influences, respectively. Similarly, cognitions or thoughts can speed (e.g., focusing on the intended movement effect) or slow motor learning (e.g., focusing on movement coordination) (Wulf, 2013). For instance, a novice windsurfer who is already a proficient surfer will have confidence in her ability to acquire the skills necessary for windsurfing. Beyond the transfer of balance-related skills, this confidence will likely reduce self-related concerns and cognitions, allowing her to focus on achieving the task goal and maintaining her balance despite perturbations from wind and water, or being watched by others. The experience of success may create positive expectations that, in turn, may further contribute to her learning progress.

The influence of a person's mindset on his or her performance can be observed easily in situations in which complex motor skills are performed, such as sports. Choking under pressure (Beilock, 2011) or flow states (Csikszentmihalyi, 1990) are well-known phenomena that have been linked to the performer's state of mind. In the former case, concerns, worries, or nervousness in challenging situations can result in a downward spiral of poor performance, ensuing conscious control attempts and self-regulatory activities, and further performance decrements. In the latter case, high confidence in one's abilities can produce the effortlessness, automaticity, and task focus seen in effective high-level performance. Is there a principal difference in how a performer's mindset influences performance at an advanced or high skill level and in the early stages of learning? Is confidence simply a "side effect" of expertise, or can confidence-enhancing measures facilitate learning in beginners? Is conscious control of movements detrimental to efficiency of expert performance but necessary, or even desirable, in novices? Or can methods that promote automaticity early enhance learning in the long-term?

It has become clear that the view of humans as processors of neutral information does not capture the breadth or variety of influences on motor behavior. The OPTIMAL theory builds on the premise that motor learning cannot be understood without considering the motivational (e.g., social-cognitive and affective) and attentional influences on behavior. We contend these influences on the performance and learning of motor skills are similar across human learners, though perhaps amplified or dampened within individuals. Presumably not coincidentally, certain motivational factors, in particular those that underlie intrinsic motivation or which satisfy fundamental psychological needs (Deci \& Ryan, 2000, 2008; Ryan \& Deci, 2000), have been found to affect performance and learning in domains beyond movement (Hagger, Sultan, Hardcastle, \& Chatzisarantis, 2015; Taylor, Jungert, Mageau, Schattke, Dedic, Rosenfield et al., 2014). We argue that those needs must be met, or at least not be threatened, in order to optimize motor learning. Broadly speaking, variables that enhance expectancies for future performance success-including those that satisfy the psychological need for competence (i.e., experiencing oneself as capable and competent) - have a beneficial effect on motor skill learning. Also, learner autonomy (i.e., the need to actively participate in determining one's own behavior) appears to influence optimal learning. Furthermore, an external focus of attention, or a concentration on the intended movement effect, enhances motor performance and learning (Wulf, 2013).

\section{Motivation}

Motivation can be a broad and inclusive term for factors influencing and encompassing the energization, direction, and intensity of behavior. It is not surprising then that the words motivation and motor [learning, behavior, performance] share the same Latin root, movere (to move). Thus, many variables - from social and other environmental conditions to internal thoughts and processes, and affective responses - can initiate or alter the direction and intensity of ongoing behavior. These motivational influences can be implicit (subliminal, primed) (Aarts, Custers, \& Marien, 2009; Chartrand \& Bargh, 2002; Ferguson \& Bargh, 2004; Radel, Sarrazin, \& Pelletier, 2009) or explicit in nature. Within the history of the study of human motivation, a number of theoretical perspectives elevate cognitions and conditions pertaining to expectations for the future as well as perceptions of autonomy to prominent motivational positions. That is, we act when future prospects provide a sense that positive outcomes will occur, and perhaps particularly when we believe we will be the agents who bring these positive outcomes to fruition. It is therefore perhaps not surprising that conditions that enhance learners' performance expectancies (see next subsection, "Enhanced Expectancies") or support their need to feel autonomous (see "Autonomy" section) facilitate motor learning.

\section{Enhanced expectancies}

Expectations carry personal histories of experiences forward in time into new contexts to allow preparation for future events. Critically, expectations are not motivationally neutral; they anticipate rewarding properties of significance to fulfilling organismic needs and desires (Schmidt, Braun, Wager, \& Shohamy, 2014). Expectations or expectancies have had prominent roles in both psychological (e.g., expectancyvalue theory, Feather, 1982; self-efficacy theory, Bandura, 1977) and neuroscientific (e.g., reward prediction error; Schultz, 1998, 2000) theorizing for decades. While lack of confidence may detract from movement fluidity or automaticity, circumstances that enhance learners' expectations of future 
performance success can potentiate even more success, improvement, and learning (Rosenqvist \& Skans, 2015). The concept of expectancies is used here to refer to a range of forwarddirected anticipatory or predictive cognitions or beliefs about what is to occur. These encompass self-efficacy and outcome expectations (Bandura, 1977), including placebos (Wager \& Atlas, 2015), as well as signals predicting extrinsic rewards (Fiorillo, Newsome, \& Schultz, 2008; Schultz, 2000). Because we focus on volitional movement, often occurring without the involvement of others, the form of expectation particularly pertinent to motor learning and performance in its individual expression is self-efficacy expectations. Self-efficacy expectations are relevant directly to the performer and the quality of the movements she or he can produce. Ostensibly, relevant expectations for the same movement task performed in different contexts (e.g., throwing a javelin in ideal environmental conditions versus in a windstorm) may involve differing impacts of selfefficacy versus outcome expectancies, depending upon the performer's control over the ultimate relevant outcome. We apply the term "confidence" as well to self-efficacy expectations. We further acknowledge that these terms may apply in the sense of collective or team efficacy (Feltz, Short, \& Sullivan, 2008), although we do not develop those arguments in the present paper. Importantly, we presume that expectations are among the motivational variables that can exert influence through implicit means (e.g., stereotype threats, goals), although deliberative, explicit, forms of these variables were originally described (Bandura, 1977; Deci \& Ryan, 1985).

Self-efficacy is an individual's situation-specific confidence or prospective sense that he or she will be able to effect the actions that bring about task outcomes (Bandura, 1977, 1997). Past success experiences, or lack thereof, are the main theoretical determinants of self-efficacy (Bandura, 1977; Lamarche, Gammage, \& Adkin, 2011; Tzetzis, Votsis, \& Kourtessis, 2008). Confidence has been recognized as a predictor of performance (Feltz, Chow, \& Hepler, 2008; Moritz, Feltz, Fahrbach, \& Mack, 2000; Rosenqvist \& Skans, 2015), and importantly, self-efficacy resulting from success experiences during the practice of a motor task is predictive of performance on subsequent tests of motor learning (Pascua, Wulf, \& Lewthwaite, 2015; Stevens, Anderson, O'Dwyer, \& Williams, 2012; Wulf, Chiviacowsy, \& Cardozo, 2014) or performance (Rosenqvist \& Skans, 2015).

Findings from a number of lines of research provide converging evidence for the effectiveness of practice conditions that enhance learners' performance expectancies. Some of these findings come from investigations into the effects of positive feedback, including social-comparative feedback and self-modeling. Other studies have provided evidence of improved performance or learning by, for instance, reducing perceived task difficulty, defining success liberally or in positive normative terms, alleviating learners' concerns, or influencing how ability is conceptualized.

\section{Positive feedback}

While feedback plays an important role in any learning process, the predominant view of augmented feedback in the motor learning literature is that it provides the learner with information about his or her performance relative to the task goal (cf. guidance hypothesis; Salmoni et al., 1984). An underappreciated function of feedback in the motor learning literature has been its influence on the performer's motivational state. In a series of recent studies, providing learners with feedback after "good" trials, compared with "poor" trials, resulted in more effective learning (Badami, VaezMousavi, Wulf, \& Namazizadeh, 2012; Chiviacowsky \& Wulf, 2007; Chiviacowsky, Wulf, Wally, \& Borges, 2009; Saemi, Porter, Ghotbi-Varzaneh, Zarghami, \& Maleki, 2012; Saemi, Wulf, Varzaneh, \& Zarghami, 2011). In those studies, feedback about task performance was given after blocks of trials. However, it was provided for only half of the trials in each block. Unbeknownst to the participants, they were given feedback about either their most or least accurate trials in that block. Groups that received feedback on the more accurate trials demonstrated more effective learning on retention tests without feedback. Thus, feedback emphasizing successful performance, while ignoring less successful attempts, benefited learning. Feedback after good trials has also been found to increase perceptions of competence (Badami, VaezMousavi, Wulf, \& Namazizadeh, 2011; Saemi et al., 2011) and self-efficacy (Badami et al., 2012; Saemi et al., 2012). The conviction that one is doing well, and the confidence in being able to perform well in the future, or their correlates such as positive affect, are conditions consistent with optimal performance and learning.

\section{Social-comparative feedback}

Providing individuals with normative information, such as the average performance scores of other learners, is a potent basis for evaluating one's own competence. Experimentally, socialcomparative information is typically provided in addition to veridical feedback about the learner's own performance (Ávila, Chiviacowsky, Wulf, \& Lewthwaite, 2012; Lewthwaite \& Wulf, 2010b; Wulf, Chiviacowsky, \& Lewthwaite, 2010, Wulf et al., 2012). Studies have demonstrated that motor learning is enhanced by (false) positive feedback, suggesting more effective performance or greater improvement than average, compared with negative feedback that indicates poorer performance relative to others, or even no socialcomparative feedback (control conditions). In one study (Lewthwaite \& Wulf, 2010b), participants who were given normative feedback suggesting that their performance on a balance task was better than average ("better" group) demonstrated more effective learning on a delayed retention test without feedback than did participants who were led to believe that their performance was worse than average ("worse" group). 
Interestingly, a control group that was not provided normative feedback showed performance and learning similar to that of the worse group. Positive normative feedback also produced qualitative differences in movement control, with participants exhibiting greater automaticity and efficiency in motor control than participants who received negative or no normative feedback. Similarly, in studies concerned with performance rather than learning, increases in movement efficiency resulting from positive social-comparative feedback were observed. Stoate, Wulf, and Lewthwaite (2012) found that favorable feedback enhanced running efficiency in experienced runners, in addition to reducing perceptions of effort. A study by Hutchinson, Sherman, Martinovic, and Tenenbaum (2008) showed greater tolerance for sustained effort in a continuous force production task, increased self-efficacy, and lower perceived exertion as a function of positive normative feedback compared with both negative feedback and control conditions. ${ }^{1}$

Positive normative feedback has been found to increase perceived competence (Ávila et al., 2012), reduce concerns and nervousness about performance and ability (Wulf et al., 2012, Experiment 1), increase satisfaction with performance and motivation to learn (Wulf, Lewthwaite, \& Hooyman, 2013), and increase positive affect (Stoate et al., 2012). In contrast, negative feedback (and perhaps control) conditions seem to trigger thoughts about the self and resulting self-regulatory activities that hamper learning of the primary task. For example, in a study by Wulf, Lewthwaite, and Hooyman (2013), participants learning a balance task who received negative normative feedback, demonstrated defensive, self-enhancing reactions to the self-related threat that was reflected in increased signature size over the course of practice. Signature size change has been interpreted as reflecting an implicit mechanism to regulate anxiety and negative affect resulting from threats to self-esteem, and increased signature sizes are seen as a sign of implicit selfesteem compensation (Rudman, Dohn, \& Fairchild, 2007).

\section{Self-modeling}

In a few studies, the effects of edited video feedback about learners' best performance (so-called self-modeling) were compared with video feedback about their actual or average performance, no video feedback (Clark \& Ste-Marie, 2007), or verbal instructions (Ste-Marie, Vertest, Rymal, \& Martini, 2011). Interestingly, learners who watched the edited videos that showed their best swimming strokes or trampoline skills demonstrated enhanced learning relative to other groups. In addition, self-modeling resulted in greater intrinsic motivation and satisfaction with performance (Clark \& Ste-Marie, 2007). These findings are consistent with the beneficial performance

\footnotetext{
${ }^{1}$ Of course, experimental use of false social-comparative feedback, though revealing of learners' needs for a sense of competence, is not recommended for direct application.
}

and learning effects of positive social-comparative feedback and its motivational consequences.

\section{Perceived task difficulty}

There are also more subtle and less expensive ways of enhancing expectancies to facilitate performance and learning than giving false feedback, editing videotapes (self-modeling), or providing rewards. In one study, older adults (average age: 64 years) - who may have concerns when expected to demonstrate abilities, such as balance, that supposedly decline with age (Hughes, Geraci, \& De Forrest, 2013) - were informed, before practicing a novel balance task, that "active and experienced persons like (them)" typically did well on that task (Wulf et al., 2012, Experiment 2). Compared with not receiving this information (control group), this simple statement resulted in increased self-efficacy and superior learning. Thus, the general comment on a peer group's performance presumably made the novel and relatively challenging balance task appear less daunting and alleviated concerns older adults may have had, elevating self-efficacy relative to a control group. Performance and learning were also facilitated.

Setting criteria that purportedly indicate good performance, but that can be reached relatively easily, can also raise learners' expectancies. Using a visuo-motor adaptation task, Trempe, Sabourin, and Proteau (2012) found that visuomotor adaptation was enhanced when participants were given a relatively easy objective or goal - and thus experienced more success during practice - relative to participants who were given a more difficult goal. As shown in Figure 1, a group with an easy goal (24-hour easy-objective) outperformed a group with a difficult goal (24-hour difficult-objective) when

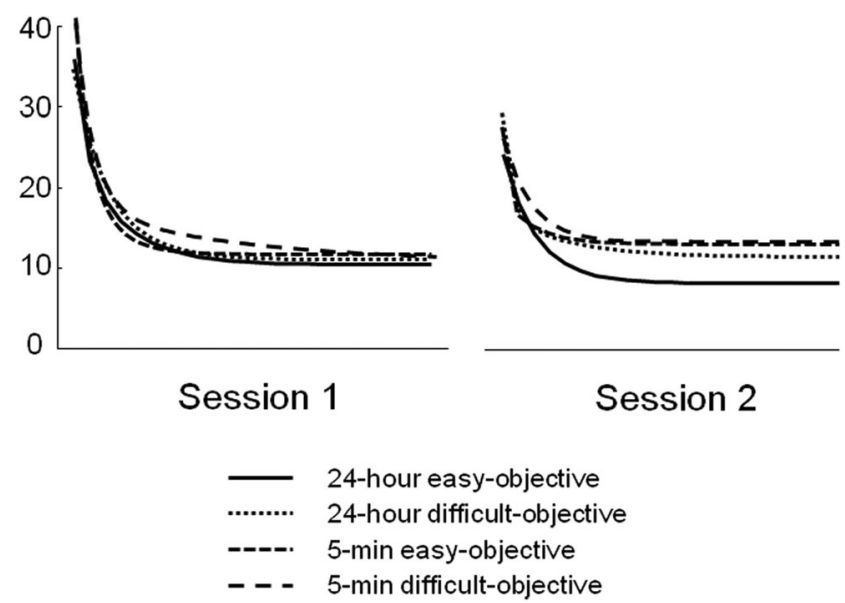

Fig. 1 Errors on a visuomotor adaptation task in the study by Trempe, Sabourin, and Proteau (2012). When given an easy goal in session 1 (24hour easy objective group), enhanced learning was seen 24 hours later (session 2). Thus, rather than actual performance during session 1 , the subjective experience of success facilitated memory consolidation. Note. From "Success modulates consolidation of a visuomotor adaptation task," by Trempe, Sabourin, and Proteau, 2012, Journal of Experimental Psychology: Learning, Memory, and Cognition, 38, p. 56 
both groups were retested 24 hours after the practice phase. The 24-hour easy-objective group also outperformed two other groups that performed the second session after 5 minutes. Thus, when memory consolidation had a chance to take place (24-hour groups), the success experienced during practice manifested itself in enhanced learning. Interestingly, this was the case even though the actual performance of the 24-hour easy-objective group did not differ from that of the other groups in the first session. Conversely, providing performers with a criterion for good performance that is difficult to reach can impair learning. Palmer, Chiviacowsky, and Wulf (2016) provided non-golfers with instructions that putting within smaller or larger concentric circles surrounding a target would constitute "good" golf putts. The group for whom the larger circle was identified putted more accurately in practice and in 24-hour retention and transfer tests than did the group with the higher standard or more conservative (smaller circle) definition of success. Chiviacowsky, Wulf, and Lewthwaite (2012) demonstrated that learners practicing a coincident-timing task, who were informed that errors within a very small bandwidth (4 ms) constituted good performance, showed less effective learning than those with a comparatively large error bandwidth $(30 \mathrm{~ms})$, or those who had not been given a criterion (control group). Self-efficacy was degraded in the 4-ms group as well.

Performance expectancies can be influenced by beliefs or suggestions that certain aids or devices will assist performance, by optical illusions, and sometimes superstition (Ashor, 2011; Damisch, Stoberock, and Mussweiler, 2010; Calin-Jageman \& Caldwell, 2014). For example, believing that a putter used to belong to a professional golfer was found to enhance putting accuracy (Lee, Linkenauger, Bakdash, Joy-Gaba, \& Proffitt, 2011). In a series of experiments using both motor (e.g., golf putting) or cognitive tasks (e.g., solving anagrams), Damisch, Stoberock, and Mussweiler (2010) demonstrated that superstition - for instance, believing in "lucky" golf balls or the effectiveness of lucky charms - enhanced performance relative to control conditions. In some of those experiments, self-efficacy was assessed before the task was performed and was found to be increased when a lucky charm was present as opposed to absent. Moreover, performance was mediated by self-efficacy (but see Calin-Jageman \& Caldwell, 2014, for a failure to replicate some of the superstition findings).

Optical illusions affecting the perceived size of the hole can influence accuracy in golf putting. As demonstrated by Witt, Linkenauger, and Proffitt (2012), when the golf hole appeared larger because it was surrounded by small circles, participants produced more successful putts than when the hole was surrounded by larger circles and therefore appeared smaller (Ebbinghaus illusion). In a follow-up study, Chauvel, Wulf, and Maquestiaux (2015) assessed participants' self-efficacy as a function of perceived hole size and used a retention test to determine to what extent the performance-enhancing effects were relatively permanent and independent of the presence of the optical illusions. Both self-efficacy and learning (i.e., retention performance without optical illusions) were enhanced in the group that practiced with a perceived larger hole compared with a group that experienced a smaller-looking hole (Figure 2). Thus, the benefits of enhanced expectancies due to the apparently larger hole during practice extended to the learning of this task. Overall, it is striking how easily performance and learning, across task domains, can be affected by performers' expectancies.

Hypnosis also may have the capacity to increase expectancies (Barker, Jones, \& Greenlees, 2010), which in turn may lead to performance or learning enhancements. In one study, even a brief (10-minute) hypnotic intervention improved throwing accuracy (Jalene \& Wulf, 2014). A group that underwent a hypnosis session, which had as a central theme the suggestion that a focus on the target would enhance accuracy, showed greater throwing accuracy on 10-minute and 1week retention tests than a control group that simply received instructions informing them about the benefits of a focus on the target.

Interestingly, suggestions that one is doing well do not have to be related to one's motor performance per se. For example, instilling the belief in individuals that they are likely to

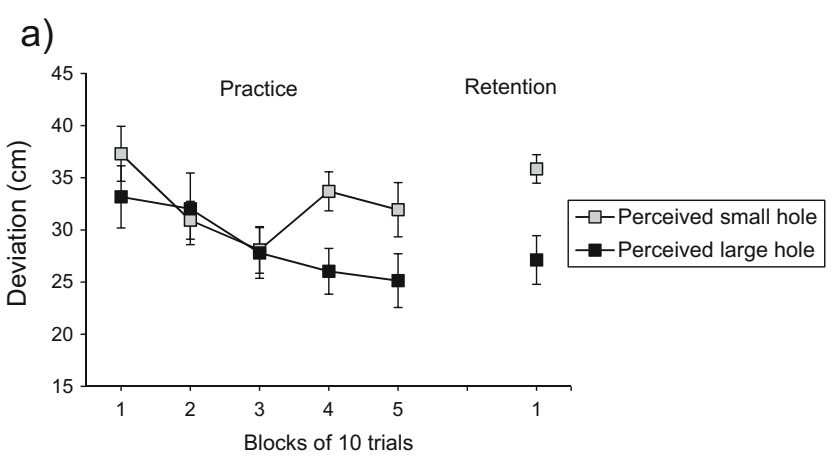

b)

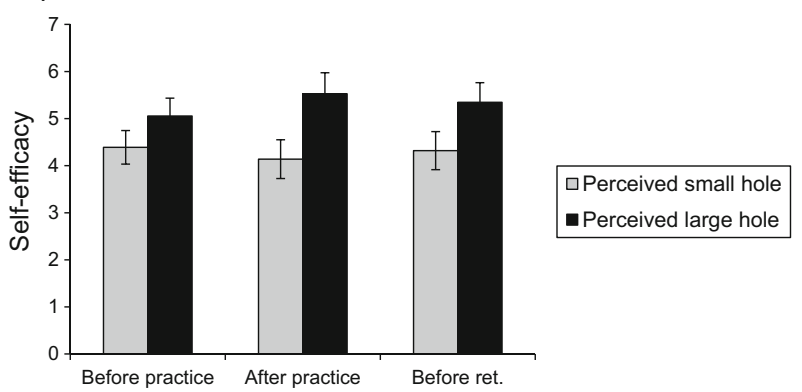

Fig. 2 Golf putting performance (a) and self-efficacy (b) of the groups for which the hole was surrounded by large circles (perceived small hole) or small circles (perceived large hole) during practice. The apparently larger hole increased self-efficacy before and after practice, and enhanced learning (i.e., retention performance). Note. From "Enhanced expectancies resulting from visual illusions can facilitate sport skill learning," by Chauvel, Wulf, and Maquestiaux, 2015, Psychonomic Bulletin \& Review, p. 720 
perform well in a certain category of situations (e.g., pressure) can result not only in a higher perceived situational ability but also in enhanced performance. In one study, enhancing performers' expectancies for generic performance under pressure increased their throwing accuracy relative to the control condition (McKay, Lewthwaite, \& Wulf, 2012). That is, motor performance was enhanced simply by suggesting to performers that they were likely to do well under pressure.

\section{Conceptions of ability}

Individuals' conceptions of abilities - that is, their views of abilities as reflecting a fixed capacity versus being amenable to change with practice (Dweck, 1999) — can affect not only their motivation to practice but also influence performance and learning more directly (Blackwell, Trzesniewski, \& Dweck, 2007; Dweck \& Leggett, 1988; Jourden, Bandura, \& Banfield, 1991; Mangels, Butterfield, Lamb, Good, \& Dweck, 2006; Wulf \& Lewthwaite, 2009). In general, people who believe that (motor) abilities are relatively fixed (so-called entity theorists), tend to be more concerned with proving their ability, and they perceive errors or negative feedback as a threat to the self, because they reveal a limited capacity or lack of ability. In contrast, people who assume that abilities are changeable or malleable (so-called incremental theorists) tend to focus more on learning and improving their performance on a given task. They are less threatened by feedback indicating errors or poor performance, and they confront difficulties by increasing their effort.

Conceptions of ability can be influenced, often relatively easily, by task instructions or performance feedback. Those that promote an entity theory tend to induce concerns about performance or abilities being measured - with important consequences for actual performance, learning, and motivation. For both types of theorists, violations of patterns of expected results have affective and motivational consequences (Plaks \& Stecher, 2007). Children's conceptions of ability for movement-relevant tasks were affected by even subtle differences in the wording of feedback (Chiviacowsky \& Drews, 2014; Cimpian, Arce, Markman, \& Dweck, 2007). In Cimpian and colleagues' study, 4-year-old children who performed a drawing task were given feedback implying that performance reflected an inherent ability ("You are a good drawer") or the effort invested in a particular picture ("You did a good job drawing"). When confronted with mistakes later, children who had received feedback that induced an entity as opposed to an incremental theory, showed diminished motivation and more negative self-evaluations. Chiviacowsky and Drews (2014, Experiment 1), examined children's motor performance and learning as a function of manipulated beliefs about the nature of ability. Ten-year-old children kicking soccer balls at a target received feedback promoting an entity ("You are a great soccer player") or incremental theory (e.g., "Those kicks were very good") in the first phase of the study. In a second phase, they were given negative feedback (i.e., shots purportedly being "not very accurate"). After the negative feedback, participants in the former condition demonstrated degraded kicking accuracy relative to the latter condition.

Ability conceptions can also influence adults' motivation and motor performance or learning. Jourden et al. (1991) informed one group of participants that a pursuit rotor task they were about to perform, which required tracking a moving cursor with a stylus, represented a learnable skill. Participants in that group showed greater self-efficacy, more positive affective self-reactions, greater interest in the task, and greater improvement across trials than did participants who were led to believe that the apparatus measured their natural capacity for processing dynamic information. Wulf and Lewthwaite (2009) examined whether instructionally induced conceptions of ability would have more permanent (i.e., learning) effects. The learning of a balance task (stabilometer) was indeed enhanced by instructions depicting performance on the task as an acquirable skill rather than something that reflected an inherent ability for balance. The acquirable-skill group showed greater improvement in balance performance across retention trials, as well as greater automaticity in the control of their movements (i.e., frequency of movement adjustments) than did the inherent-ability group. Control group participants without ability-related instructions demonstrated similar performance and learning as the inherent-ability group and therefore were less effective and efficient than participants who viewed the task as a learnable skill. Drews, Chiviacowsky, and Wulf (2013) found similar effects in 6-, 10-, and 14-year-old children. Children of all age groups showed less effective learning of a throwing task when the instructions given before the practice phase suggested that performance was a reflection of an inherent ability rather a function of practice.

Conceptions of abilities may affect the extent to which people frame and interpret performance fluctuations as successes and failures, which may in turn influence motor performance and learning. Some support for this notion comes from a study by Wulf, Lewthwaite, and Hooyman (2013). Using a stabilometer balance task, these authors found that instructions inducing an entity theory led to an increase in participants' nervousness before and while balancing (during practice), as well as more thoughts about their performance and ability, and a greater focus on body movements (during retention and transfer). Individuals who see task performance as a reflection of an inherent ability presumably approach practice situations with a certain degree of apprehension (low expectations) that hinders the learning process. This also may be the case for performers whose concerns are not alleviated by information about the malleability of skills (control conditions). In contrast, individuals who believe that skills are acquirable are more likely to approach a task as an opportunity to improve, and to see errors as temporary and as being part of learning. 


\section{Extrinsic rewards}

If rewards are experienced as an index of performance effectiveness, intrinsic motivation and personal performance expectancies are likely enhanced (Eisenberger, Pierce, \& Cameron, 1999). Importantly, rewards appear to exert their effects via expectation rather than receipt. That is, it is the anticipation of reward (broadly defined) or reward prediction error (Schultz, 2000, 2013) that places this form of enhanced expectancies within our consideration here.

A few human behavioral studies have examined the effects of extrinsic rewards on motor behavior and learning. Those behavioral studies corroborate the findings reviewed above for other approaches to enhancing expectancies. For instance, the prospect of a monetary incentive has been shown to improve movement performance in persons with Parkinson's disease (Kojovic, Mir, Trender-Gerhard, Schneider, Pareés, Edwards et al., 2014; Kühn, Brücke, Hübl, Schneider, Kupsch, Eusebio et al., 2008) and to increase force production in healthy participants (Pessiglione, Schmidt, Draganski, Kalisch, Lau, Dolan et al., 2007). Abe and colleagues (Abe et al., 2011) found that a group receiving monetary rewards for good performance on a tracking task during practice showed more effective learning than a group that was punished for poor performance (by having money deducted) or a control group. Interestingly, all groups demonstrated similar performances immediately after the practice phase. However, 6 hours later, the rewarded group outperformed the other two groups and, in contrast to the punished and control groups, even showed performance gains after 24 hours and 30 days.

\section{Positive affect}

Positive affect is likely to accompany most experiences that produce enhanced expectancies for valued outcomes. One would expect heightened positive affect with desired outcomes including performance success, satisfaction of fundamental psychological needs, and extrinsic reward. In most cases, positive affect and positive cognitions would likely be co-effects of the same positive events or experiences. Anticipation of positive affect may be one relevant form of enhanced expectancies with the potential to influence performance and learning. Research directed at the impact of positive affect on cognitive processes has documented increased cognitive flexibility and creativity (cognitive performance) effects (Ashby, Isen, \& Turken, 1999; Dreisbach \& Goschke, 2004; Lyuborminsky, King \& Diener, 2005). Distinct from performance-generated positive affect, Ridderinkhof and colleagues (Ridderinkhof, van Wouwe, Band, Wylie, Van der Stigchel, van Hees, Buitenweg et al., 2012) found that positive mood inductions benefited cognitive processing in persons with Parkinson's disease. Participants showed increased positive affect after watching a Charlie Chaplin slapstick film clip and enhanced performance on a subsequent decision-learning task. By its nature, to anticipate positive affect is to anticipate a pleasant and rewarding experience. It also is conceivable that the expression of or invitation for positive affect enhanced the participants' sense of agency and thus expectations of positive outcomes (Gentsch \& Synofzik, 2014; see "Autonomy" section).

To our knowledge, there has been no claim that positive affect itself uniquely indexes dopamine release; expectations of other desirable cognitive experiences also are associated with dopaminergic response. Berridge (2007) contends that dopamine is not associated with the hedonic "liking" of rewards, but rather with the "wanting" of rewards, which might suggest that positive affect per se, unrelated to performance-associated positive emotional reactions, may in itself be rewarding but not be the driver of a large range of rewarding effects on performance and learning (but see Ridderinkhof et al., 2012).

\section{Interim summary: enhanced expectancies}

Human beings appear to have a propensity to prefer positive information about themselves, such as positive feedback about their performance (Chiviacowsky \& Wulf, 2007) or physical fitness, athleticism, health, and physical attractiveness (Ennigkeit \& Hänsel, 2014). While these preferences may simply imply a preference for states of positive over negative affect without performance implications, they may reflect people's (implicit) knowledge of the beneficial consequences of this type of feedback for motivation, performance, and learning. As reviewed above, within the motor learning domain evidence from various lines of research indicates that enhancing performance expectancies facilitates learning. Findings of enhanced self-efficacy, increased task interest or satisfaction with one's performance, reduced concerns about one's performance or abilities, and greater positive affect, support the notion that the observed learning benefits are mediated by motivational factors. It is also worth noting that, when control conditions were included - for example, in studies using social-comparative feedback (Lewthwaite \& Wulf, 2010b), providing information about the performance of peers (Wulf et al., 2012), or inducing conceptions of ability (Wulf \& Lewthwaite, 2009) - learning also was suboptimal. These findings suggest that control conditions are not, in fact, "neutral" (or at least not affirmatively positive). Experimental settings after all are public places and as such presumably induce worries about one's performance or abilities being observed, measured, and compared with those of others-leading to less-than-optimal learning.

\section{Mechanisms for enhanced expectancy effects}

Interest in expectancy-performance relationships has long been prominent in social and sport psychology. Heightened expectations result from performance accomplishments 
(Bandura, 1977), but expectations have also been experimentally and prospectively linked to motor performance (Feltz, Chow, \& Hepler, 2008; Hutchinson et al., 2008; Moritz et al., 2000; Neiss, 1989; Wulf et al., 2012).

Prospectively, expectancies for personal performance appear to serve a task-readying function. We would be merely reactive, and not proactive, without predictive and probabilitybased mechanisms that prepare us for action. Self-efficacy expectations influence goals set and generate goal setting (Theodorakis, 1995; Locke \& Latham, 2006). Perceptions of self-efficacy are related to affective self-reactions and related self-regulatory activity (Bandura \& Jourden, 1991; Jourden, Bandura, \& Banfield, 1991; Themanson, Pontifex, Hillman, \& McAuley, 2011). Task enjoyment (Hutchinson et al., 2008) and positive affect as assessed by the Positive and Negative Affect Schedule (PANAS; Watson, Clark, \& Tellegen, 1988) also have been related to conditions that enhance expectancies (Stoate et al., 2012). However, it is not known whether these cognitive and affective impacts are co-effects or integral aspects of a confident state of mind. Self-efficacy or confidence is more than just a consciously experienced perception or belief in one's own situation-specific capabilities. The affective feeling or sense of confidence is likely coincident with the self-percept or cognition of confidence. Watson and Clark (1999) included the affective dimension of self-confidence (self-assured) in the expanded version of the Positive and Negative Affect Schedule (PANAS-X). The generation of positive affect by the cognition of confidence may trigger affective consequences relevant to performance and learning.

Beyond goal setting and positive affect with enhanced expectancies, a number of other preparatory-like effects of expectancies have emerged (Rowe, Eckstein, Braver, \& Owen, 2008). For example, expectancies can influence performance through proactive effects on effort expenditure (Fiorio, Andani, Marotta, Classen, \& Tinazzi, 2014; Hutchinson et al., 2008) and on perception (Abrams \& Weidler, 2015; Chauvel et al., 2015; Piedimonte, Benedetti \& Carlino, 2015; Witt, South, \& Sugovic, 2014). Perception, rather than being a pure reflection of objective sensory reality, incorporates perceivers' assessments of their own and relevant others' abilities (Linkenauger, Witt, Stefanucci, Bakdash, \& Proffitt, 2009; Witt et al., 2014). Perceived task demands, therefore, can in effect be altered because of a performer's confidence in his or her capabilities (Chauvel et al.) or in a placebo's effect (Piedimonte et al.). Action-specific perception may serve as preparation for task performance, potentially sustaining focus on achievable elements and reducing concern about abilities to meet demands, thus freeing up self-regulatory resources for performance.

Movement-system readying occurs through pre-movement excitation or inhibition of neuromuscular systems relevant to upcoming movement execution. These, including the corticospinal tract, have been recently attributed to expectations (Arias, Robles-García, Espinosa, Corral-Bergantiños,
Mordillo-Mateos, Grieve et al., 2014; Mooshagian, Keisler, Zimmermann, Schweickert, \& Wassermann, 2015; van Elswijk, Kleine, Overeem, \& Stegeman, 2007). Similarly, suppression of activity related to unanticipated response options has been found (Klein, Petitjean, Olivier, \& Duque, 2014).

Expectancies can affect attention and cognition. Expectations can influence working memory, long-term memory, and attentional capture, biasing them toward expected stimuli (Bollinger, Rubens, Zanto, \& Gazzaley, 2010; Jiao, Du, He \& Zhang, 2015; Shomstein \& Johnson, 2013). Themanson and colleagues studied the relationship of self-efficacy to task-related attention processes in the context of flanker task performance (Themanson, Hillman, McAuley, Buck, Doerksen, Morris, et al., 2008; Themanson \& Rosen, 2015). Higher self-efficacy was associated with greater attention to task error cues (Themanson et al., 2008) and greater response accuracy during task execution with faster reaction time (RT) during more difficult or incongruent task conditions (Themanson \& Rosen, 2015).

Within the set of "enhanced expectancy" variables we discuss, outcome expectations and external rewards provide the majority of the direct evidence of dopaminergic mediation (Lidstone, Schulzer, Dinelle, Mak, Sossi, Ruth et al., 2010; Wager \& Atlas, 2015). Outcome expectancies are central in the placebo response in which individuals expect that pharmacological and other interventions will lead to beneficial outcomes (Ashor, 2011; de la Fuente-Fernandez, 2009; Lidstone et al., 2010; Wager \& Atlas, 2015). Outcome expectations for clinical improvement were altered for individuals with mild to moderate levels of Parkinson disease (PD) by verbal information concerning the probability of receiving an effective pharmacological treatment for their PD symptoms (Lidstone et al., 2010). Four groups of participants received information indicating that they had a $25 \%, 50 \%, 75 \%$, or $100 \%$ chance of receiving levodopa (a dopamine agonist commonly prescribed for PD). All groups received a placebo. The group led to believe they had a strong but not certain (75\%) expectation of levodopa receipt experienced dopamine release in their ventral and dorsal striata consistent with their measured dopamingeric responses to actual levodopa.

High performance expectancies, as described above, appear to prepare the mover for successful movement through diverse effects at cognitive, motivational, neurophysiological, and neuromuscular levels - ensuring that goals are effectively coupled with desired actions. In the moments when action is planned and executed, higher performance expectancies may also serve as a buffer or protection against responses that would detract from optimal performance, such as nonbeneficial alternate responses, including off-task activity (Jiao et al., 2015; Zahodne, Nowinski, Gershon, \& Manly, 2015) or self-referential thinking. The dual role of enhanced expectancies for goal-action coupling - maintaining a focus on the task goal and preventing or reducing a self-focus (or other off-task activity) - is indicated in the schematic of the 
OPTIMAL theory in Figure 3. Of course, the obverse may be true: low personal expectations for a positive outcome may activate conflicting responses or act in the manner of a selfinvoking trigger (see section on "External Focus of Attention"; McKay, Wulf, \& Lewthwaite, 2015), inviting potentially taskincompatible concerns, anxiety, negative affective reactions, and neuromuscular activity, necessitating resource deployment to self-regulation and recovery. Conceptually at least, it also is possible to hold such high expectations that preparation and attention to the task at hand seem superfluous and concentration and commitment may suffer (Feltz \& Wood, 2009).

Desirable experiences and outcomes produce psychological recognition, in the form of positive cognitions (e.g., efficacy and outcome expectations) and associated positive affective responses. A common substrate to consciously or subliminally registered conditions that signal success, enhance expectations of extrinsic rewards, support psychologicalbiological fundamental needs including competence, autonomy, and social-relatedness (Baumeister \& Leary, 1995; Deci \& Ryan, 2008; Leotti, Iyengar, \& Ochsner, 2010; White, 1959), and create positive affect, or several of the above (Koepp, Gunn, Lawrence, Cunningham, Dagher, Jones et al., 1998) may be the elicitation of a response in the dopamingeric system. While the expectation of reward has received particular attention as a trigger for a dopamine response (Schultz, 2013), other related cognitive-affective states are supported as well (Schultz, 2010). These triggers and states include novelty and other violations of expectations (Costa, Tran, Turchi, \& Averbeck, 2014; Duzel, Bunzeck, Guitart-Masip, \& Duzel, 2010; Murty \& Adcock, 2014), active video game play (Koepp et al., 1998), stress (Lighthall, Gorlik, Schoeke, Frank, \& Mather, 2013), and risk (Schultz, 2010). In the neuroscience tradition that stems from origins in animal work, extrinsic rewards, such as food, water, and money, have been predominant in the study of dopamine responses. Importantly, as noted by Schultz, "Although rewards have objective, physical, and chemical properties, their value is defined by the needs of the individual decision maker and thus intrinsically subjective.... The data suggest that both subjective perception and physical presence of a stimulus are necessary to evoke dopamine responses, whereas physical presence alone is insufficient" (Schultz, 2013, pp. 231-232).

Dopaminergic systems subserve brain activity relevant to motor, cognitive, and motivational functioning and include the mesocortical, mesolimbic (often combined into the mesocorticolimbic), and nigrostriatal dopamingeric systems (Nieoullon \& Coquerel, 2003; Wise, 2004). The mesolimbic dopaminergic system is associated with the reward or motivation system (a component of the salience network; Menon, 2015, see later section on "Goal-action coupling: a common mechanism for motivational and attentional effects on motor performance and learning") and is centered in the subcortical ventral striatum that includes the nucleus accumbens, ventral tegmental area, and globus pallidus. The nigrostriatal dopaminergic system, centered in the dorsal striatum, has been associated with working memory and motor system functions, such as motor planning and response selection. Importantly, the latter system receives projections from the former (Draganski,B., Kherif, F., Kloppel, S.,Cook, P. A.,Alexander,D.C., Parker et al., 2008; Schmidt, Lebreton, Clery-Melin, Daunizeau, \& Pessiglioni, 2012; Yin, Ostlund, Balleine, 2008), which may interact with the motor system, including the primary motor cortex, via other direct and indirect pathways (Hosp, Pekanovic, Rioult-Pedotti, \& Luft, 2011). We should note that the identification of a potential common denominator in dopaminergic response, however, does not negate recognition of the complexity of neurophysiological influences on performance and learning (Boureau \& Dayan, 2011; Lancaster, Heerey, Mantripragada, \& Linden, 2015).

While dopamine neurons predominantly signal some manner of positive reward and expected success is therefore important, a smaller set of dopamine neurons is responsive to negative signals. Occasional risks to expected rewards (i.e., challenge) can transiently dampen the extant levels of rewardrelated dopamine but amplify the impact of subsequent

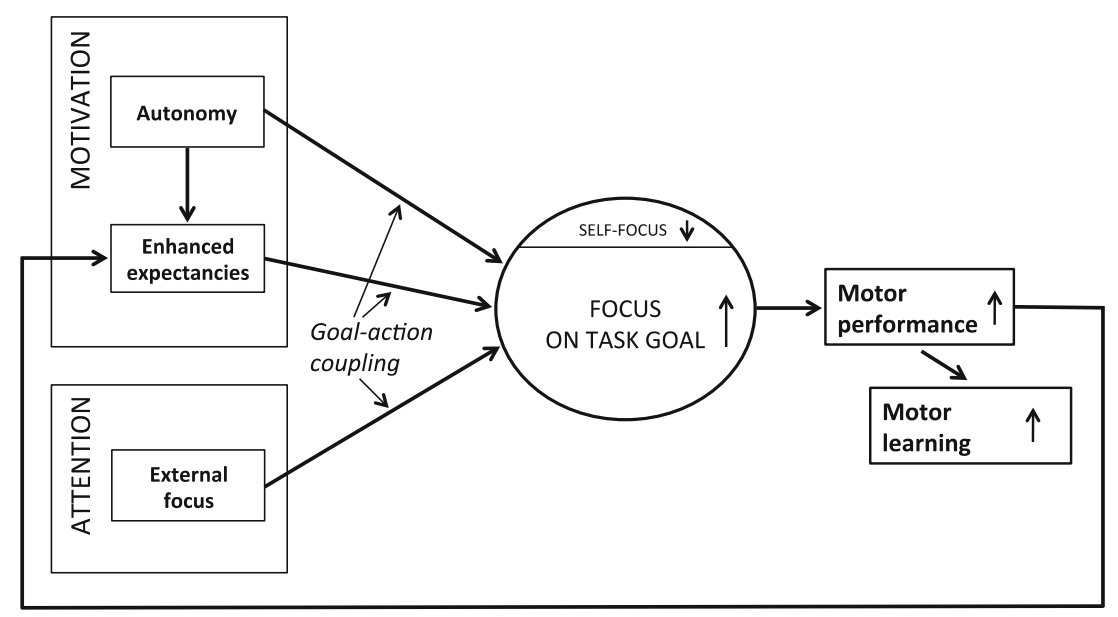

Fig. 3 Schematic of the OPTIMAL theory 
positive (but not negative) cues, strengthening the learning effect (Schultz, 2010, 2013). It is conceivable that the potentiating effect of success with challenge on the strength of the resultant dopamine response may give rise to a variety of beneficial learning and memory effects often attributed to challenge or task difficulty per se (Lee, Swinnen, \& Serrien, 1994). Behaviorally, as well, challenge or stress may alert learners to increase effort and attention to the task, improving performance. A number of disparate but intriguing effects also point to the potency of success with challenge, particularly over challenge alone. For example, Finn and Miele (2015) found that test takers preferred longer tests of difficult math problems with starting or ending sets of moderately difficult (successful) items to shorter tests of the same difficult math problems only. Interestingly, in the hippocampus, learning, but not training per se, rescues or increases the survival of newly generated cells into differentiated neurons to the extent that the learning experience is new, effortful, and importantly successful (Shors, 2014).

\section{Autonomy}

Allowing individuals to exercise control over the environment may not only satisfy a basic psychological need (Deci \& Ryan, 2000; 2008; White, 1959) but may be a biological necessity (Leotti \& Delgado, 2011; Leotti, Iyengar, Ochsner, 2010). Studies with both humans (Tiger, Hanley, \& Hernandez, 2006) and other animals (Catania, 1975; Catania \& Sagvolden, 1980; Voss \& Homzie, 1970) have shown that both prefer an option leading to a choice than an option that does not, even if this option results in greater effort or worksuggesting the existence of an inherent reward with the exercise of control (Karsh \& Eitam, 2015; Leotti \& Delgado, 2011). Along the same lines, Eitam, Kennedy, and Higgins (2013) demonstrated that human motivation is dependent on (the perception of) one's actions having effects on the environment. Even if the effects of one's actions are trivial, intrinsic motivation is enhanced if the performer has control over those effects (termed Control Effect Motivation by Eitam et al.). Conditions that provide an opportunity for choice may be motivating, because they indicate that one will be able to control upcoming events.

Consistently, studies in the motor learning literature have shown that giving the learner control over certain aspects of the practice conditions enhances motor skill learning (for reviews, see Sanli, Patterson, Bray, \& Lee, 2013; Wulf, 2007b). Also, the type of instructional language (i.e., autonomy-supportive, controlling) has been found to have an impact on motor learning. Perhaps most interestingly, giving learners choices - even it if they are incidental to the task - can influence learning. These findings are reviewed next.

\section{Control over practice conditions}

Learning benefits of self-control have been found for control in the forms of the delivery of feedback, augmented task information, use of assistive devices, movement demonstrations, amount of practice, task order, etc. Studies examining effects of self-controlled practice usually involve a yoking procedure, in which each participant in a self-control group is paired with another participant in a yoked group. A participant in the yoked group receives feedback, for example, on the same trials as did their counterpart in the self-control group. Thus, because the frequency and timing of feedback delivery, etc. is controlled for and identical for both groups, any group differences that emerge on retention or transfer tests can be attributed to the fact that one group had control over a certain variable, while the other group did not.

Enhanced learning with self-controlled feedback has been found with various movement tasks, including throwing tasks, in which feedback was provided about movement form (Janelle, Barba, Frehlich, Tennant, \& Cauraugh, 1997) or the accuracy of the throws (Chiviacowsky, Wulf, Laroque de Medeiros, Kaefer, \& Tani, 2008). Other researchers have found learning advantages of self-controlled feedback for timing tasks (Chen, Hendrick, \& Lidor, 2002; Chiviacowsky \& Wulf, 2002; Patterson \& Carter, 2010). Self-controlled concurrent feedback has been shown to facilitate the learning of perceptual invariants (i.e., adjusting walking speed when walking through virtual opening and closing doors) (Huet, Camachon, Fernandez, Jacobs, \& Montagne, 2009) and landing a virtual aircraft (Huet, Jacobs, Camachon, Goulon, \& Montagne, 2009).

In situations in which learning the correct movement sequence is challenging (e.g., dance routines, sign language, typographical script), information or reminders about the movement pattern to be executed are sometimes provided to the learner. In a study using a Graffiti language learning task, which involved entering symbols into a personal digital assistant when prompted by the English-script cue, learners allowed to decide when they wanted to view the correct pairing of the English cue and respective symbol, as well as the viewing duration, before entering the symbol, outperformed their yoked counterparts (Patterson \& Lee, 2010).

When learners are given control over the use of physical assistive devices on balance tasks, learning was enhanced relative to the externally controlled use of those devices (yoked conditions) (Chiviacowsky, Wulf, Lewthwaite, \& Campos, 2012; Hartman, 2007; Wulf, Clauss, Shea, \& Whitacre, 2001; Wulf \& Toole, 1999). For example, in one study participants practiced a ski-simulator task and had, or did not have, the opportunity to decide on which trials to use poles that were placed on the floor to help them maintain their balance (Wulf $\&$ Toole). The participants in the self-controlled group showed more effective learning, as measured by performance on a retention test without the poles, than did their yoked counterparts. 
In other studies (Chiviacowsky et al., 2012a; Hartman, 2007), learning to balance on a stabilometer platform was facilitated by holding a balance pole horizontally when the use of that pole was chosen by the participants rather than imposed upon them. This finding is particularly interesting because, in a pilot study, Hartman did not find advantages to using the poles for the learning of this task, suggesting that control over an assistive device can have a beneficial effect on learning, even if that device in and of itself is relatively ineffective. Chiviacowsky and colleagues found similar learning benefits of self-controlled pole use for persons with Parkinson's disease. Questionnaire results in that study revealed that participants who were given a choice regarding the use of the pole felt less nervous and were less concerned about their body positions.

Observational learning, that is, watching another performer demonstrate a goal movement, is a commonly used and effective way of learning motor skills (for reviews, see Maslovat, Hayes, Horn, \& Hodges, 2010; Ong \& Hodges, 2012). In a study by Wulf, Raupach, and Pfeiffer (2005), participants practiced a basketball jump shot, and a video of a skilled model could either be requested by them or was provided to them at the respective times during practice. After a 7-day retention interval, the self-control group showed superior movement form compared with the yoked group.

\section{Instructional language}

The way in which task instructions are worded - that is, whether the language is autonomy-supportive or controlling-has been shown to influence motor learning (Hooyman, Wulf, \& Lewthwaite, 2014), perhaps through the down-regulatory effect of cortisol on the brain's reward circuitry (Montoya, Bos, Terburg, Rosenberger, \& van Honk, 2014). Hooyman et al. followed up on a study by Reeve and Tseng (2011), in which instructions related to a puzzle task that was unsolvable in the time available led to differential cortisol responses when they were worded in an autonomysupportive rather than controlling way. Hooyman and colleagues varied the way in which instructions for performing a modified cricket bowling action were presented. Instructions that gave the participant a sense of choice (i.e., autonomysupportive language) led to superior learning than those that offered little option for how to execute the bowling action, etc. (i.e., controlling language). As shown in Figure 4a, throwing accuracy during both practice and retention was higher for the group that received autonomy-supportive rather than controlling language instructions during practice.

\section{Incidental Choices}

Allowing learners to choose the extent of practice or the spacing of practice trials has been found to lead to more effective learning than yoked control conditions (Post, Fairbrother, \& Barros,
2011; Post, Fairbrother, Barros, \& Kulpa, 2014). Letting participants choose the order in which they wanted to perform balance exercises resulted in more effective learning of those exercises than not giving them this choice (Wulf \& Adams, 2014). In a case study with a professional kickboxer, letting him choose the order of punches resulted in greater punching velocity and impact forces than a prescribed order of punches (Halperin, Chapman, Martin, \& Wulf, 2015). In addition, choice of exercise order can increase performers' willingness to complete more repetitions (Wulf, Freitas, \& Tandy, 2014), which may provide an additional indirect benefit to learning.

Importantly, even giving individuals choices that are incidental to the motor task has been demonstrated to have a positive effect on the learning of that task (Lewthwaite, Chiviacowsky, \& Wulf, 2015). In one experiment, allowing participants to choose the color of golf balls they were putting led to more effective task learning than a yoked condition. Giving participants a choice of ball color also has been found to increase the learning of a throwing task (Wulf, Chiviacowsky, \& Cardozo, 2014). In a second experiment by Lewthwaite et al., the findings were even more compelling: The learning of a balance task (stabilometer) was enhanced in a group in which participants were given a choice related to one of two tasks they would practice afterwards and in which they were asked their opinion as to which of two prints of paintings should be hung in the laboratory. That is, relative to a yoked group that was simply informed of the second task or the print to be hung, the choice group demonstrated more effective retention performance on the balance task.

\section{Interim summary: autonomy}

As outlined above, providing learners with control, or supporting their need for autonomy, has been found to enhance learning in numerous studies. Independent of which factor the learner is given control over - or whether this factor is even related to the task to be learned - the learning benefits appear to be very robust and generalizable to different tasks, age groups, and populations. Its broad impact on motor learning seems to suggest that autonomy support may exert its influence in various ways. Many possible explanations have been suggested for the learning benefits of granting learners control over practice conditions. For example, it has been suggested that a more active involvement of the learner in the learning process promotes deeper processing of relevant information (McCombs, 1989; Watkins, 1984; Chen \& Singer, 1992); encourages error estimation (Chiviacowsky \& Wulf, 2005); fosters the use of self-regulation strategies (Kirschenbaum, 1984); or that giving the learner control over the practice conditions might be, in a general sense, more motivating (Bandura, 1993; Boekaerts, 1996). Increased task interest (Lewthwaite et al., 2015) and motivation to learn (Chiviacowsky, Wulf, Lewthwaite, \& Campos, 2012) when learners are given a choice has indeed been found. Yet, we contend that the perception of 
a)

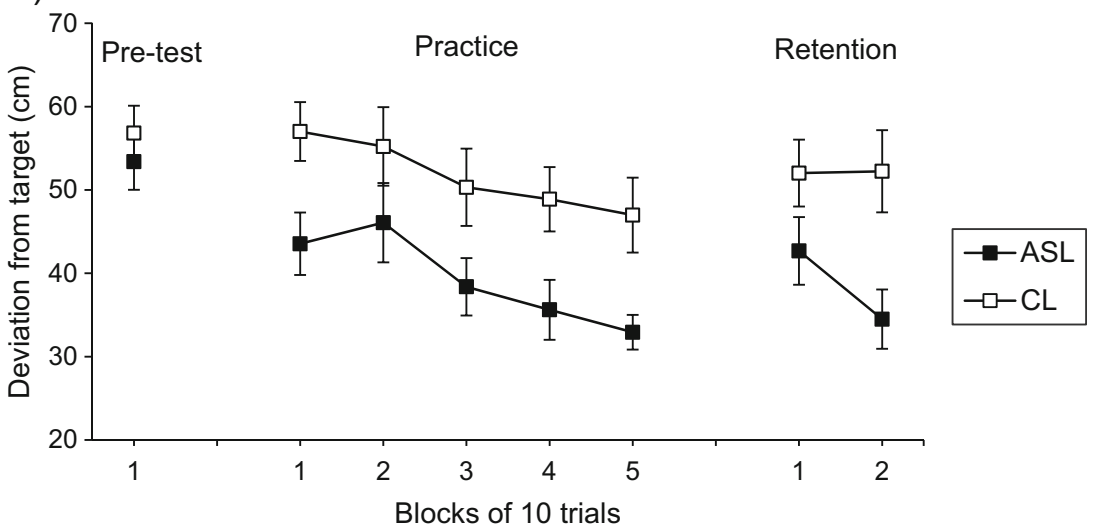

b)

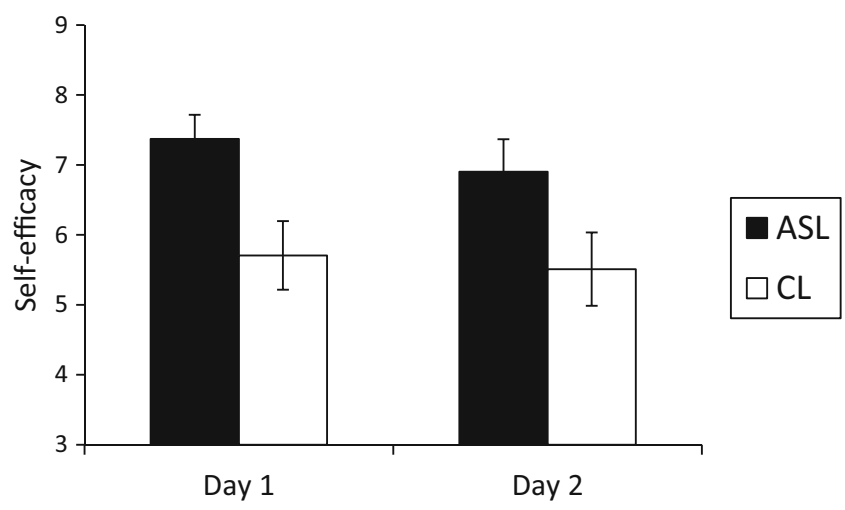

Fig. 4 Performance on a cricket bowling action task (i.e., target deviations) (a) and self-efficacy (b) as a function of autonomysupportive (ASL) or controlling language (CL) instructions. Note. From

autonomy has a more direct impact on learners' motivational state and, consequently, their motor control and learning.

\section{Mechanisms for autonomy-support effects}

Potential consequences of autonomy-supportive conditions include facilitation of performance (Karsh \& Eitam, 2015; Legault \& Inzlicht, 2013) as well as the opportunity to enhance perceptions of competence, self-efficacy, and sense of agency (Chambon \& Haggard, 2012). Legault and Inzlicht examined in separate studies autonomous motivation (trait autonomy; see also Ryan \& Deci, 2000) and an autonomy-supportive condition as they affected the magnitude of the error-related negativity response to performance errors in Go/No-Go and Stroop tasks requiring performance inhibition for accurate responding. Autonomy was associated with greater self-regulatory responsiveness to task errors than controlling motivation and conditions, and in meditational analysis, to better performance.

Indirect effects of autonomy-supportive conditions include the opportunity to enhance expectations for performance. Indeed, learners able to control the delivery of feedback, typically report asking for feedback when they assumed their performance was relatively successful. Groups with self-
"Impacts of autonomy-supportive versus controlling instructional language on motor learning," by Hooyman, Wulf, and Lewthwaite, 2014, Human Movement Science, 36, p. 194-195

controlled feedback tend to receive feedback more after good trials (i.e., with smaller errors) than after poor trials compared with control groups (Chiviacowsky \& Wulf, 2002; Chiviacowsky, Wulf, Medeiros, Kaefer, \& Tani, 2008; Patterson \& Carter, 2010; Patterson, Carter, \& Sanli, 2011). Thus, one reason for the effectiveness of self-controlled conditions may be that they have the potential to enhance learners' self-efficacy (Wulf, Chiviacowsky, \& Cardozo, 2014; Wulf, Chiviacowsky, \& Drews, 2015). Support for this notion also comes from a study in which learners' perceptions of competence in a self-controlled feedback condition were thwarted by informing them that only performances within a very small error range (i.e., $4 \mathrm{~ms}$ or less on an anticipationtiming task) were considered successful (Chiviacowsky, Wulf, \& Lewthwaite, 2012). Compared with self-control groups that were not provided a performance criterion or were given a criterion that was easier to reach $(30 \mathrm{~ms})$, self-efficacy was lower in that group and learning was degraded. Thus, when given the opportunity, learners appear to use feedback as a means to protect or enhance their perceptions of competence.

Similarly, the use of assistive devices (Chiviacowsky, Wulf, Lewthwaite, \& Campos, 2012; Hartman, 2007; Wulf $\&$ Toole, 1999) or the ability to review solutions to problems 
before entering them (Patterson \& Lee, 2010) may allow learners to maintain or increase their self-efficacy. Some evidence for a reduced self-focus (resulting from the presumed increase in self-efficacy) comes from findings that participants, who were able to control their use of a balance pole on the stabilometer task (Chiviacowsky, Wulf, Lewthwaite, \& Campos, 2012), reported being less nervous before a trial and while balancing, compared with their yoked counterparts. Furthermore, they indicated that they were less concerned about the position of their body parts, suggesting that they were less likely to adopt a self-focus.

Interestingly, self-efficacy can also be increased by autonomy-supportive relative to controlling task instructions (Hooyman et al., 2014, Reeve \& Tseng, 2011). In Reeve and Tseng's study, using a puzzle-solving task, participants in the autonomy-supportive group reported higher perceived competence than did participants in either the neutral or controlling group (which did not differ from each other). Also, in the Hooyman et al. study, self-efficacy was higher when participants learning a cricket bowling action were given instructions that provided them with a sense of autonomy (or neutral instructions), compared with controlling instructions (Figure 4b). Furthermore, in both studies, perceived autonomy or choice was significantly correlated with self-efficacy. It seems likely that autonomy-supportive conditions instill a generalized sense of agency for learners that increases their own confidence in being able to do well on a given task. Thus, autonomy support directly affects performance and indirectly contributes to goal-action coupling by enhancing performance expectancies. These contributions are indicated by the arrows from autonomy support in Figure 3.

One mechanism through which the assumption of heightened causality or sense of agency may occur is known as the intentional binding effect (Haggard, Clark, \& Kalogeras, 2002). Intentional binding refers to the linking of an environmental effect with the agent's intent to produce it, an awareness that occurs only when actions are volitional or intentional. Intentional binding is affected by temporal contiguity of intent and action (Haggard et al.) and is used as an index of a sense of agency. Thus, when an effect occurs soon after the agent's intent and action, agency is expected and assumed. Sense of agency is affected by exerted effort (Demanet, Muhle-Karbe, Lynn, Blotenberg, \& Marcel Brass, 2013), anticipated affect (Frith, 2014), perceived task success (Dewey, Seiffert, \& Carr, 2010), and ease of action selection such as occurs when stimulus and response are compatible (Chambon \& Haggard, 2012).

Given people's psychological and presumably biological need for autonomy (Deci \& Ryan, 2000, 2008; Leotti et al., 2010), controlling environments tend to induce stress (Reeve \& Tseng, 2011) and, presumably as a result, self-regulatory attempts at controlling emotional responses. One consequence of external control attempts can be behavior that is opposite to the behavior that is desired (Stephens, Franks, Rook, Iida,
Hemphill, \& Salem, 2013). Psychological stress and/or subsequent control attempts would be expected to take attentional capacity away from the task and result in degraded learning. Some evidence for negative emotional consequences in response to a controlling environment comes from the study by Reeve and Tseng. These authors measured cortisol levels as a function of "teaching style" (i.e., autonomy-supportive, controlling, or neutral instructions related to a puzzle-solving task). Cortisol is considered a stress hormone, and increased levels are thought to reflect coping processes in response to the stress (Dickerson \& Kemeny, 2004). Even though Reeve and Tseng did not assess performance on the puzzle task, designed to be unsolvable in the provided time, the controlling instructional style increased salivary cortisol, whereas an autonomysupportive style decreased it relative to a neutral style. In a subsequent study using a novel version of a cricket bowling action, Hooyman et al. (2014) found that learning was enhanced with autonomy-supportive instructions (e.g., “...you may want to cradle and deliver the ball in a windmill fashion so the ball travels over the shoulder and not to an angle or to the side.") compared with controlling instructions (e.g., “...you must cradle the ball so it travels in a circular pattern. At the apex of the pitch the ball must be directly over the shoulder. Do not throw it at a side angle."), whereas a neutral-language condition ("...cradle and swing the ball so it travels in a circular fashion before it is released. Before the release of the ball, make sure it travels over the shoulder.") did not differ from either one. These results lend support to the idea that learning is degraded in situations that do not meet learners' need for autonomy, in part because self-regulatory activity in response to external control attempts interferes with learning.

To this point, we have discussed a variety of "positive" motivational influences on motor performance and learning, including intrinsic (perceived competence, self-efficacy, perceived control) and extrinsic (external rewards, monetary incentives) forms. We have not generally distinguished between these types of motivation, in part, because the psychological and neuroscientific evidence does not yet identify consistent differences between forms of positive motivation, mediating mechanisms (e.g., dopamine), and performance outcomes. However, when additional dependent variables, such as whether or not participants return to the task when they are free to do so (free choice behavior), and task engagement are considered, some divergence in effects occurs. In psychological science, the undermining impact of extrinsic rewards on intrinsic motivation, such as that demonstrated when external rewards are provided after performance but removed subsequently, is well known (Deci, Ryan, \& Koestner, 1999; White \& Sheldon, 2014). It is assumed to reflect the controlling aspects of reward on behavior.

Recently, Murayama and colleagues demonstrated the undermining effect of reward on subsequent free choice behavior and neural activation, finding more limited engagement in the task and reduced activation in the anterior striatum, 
midbrain, and lateral prefrontal cortex following reward (Murayama, Matsumoto, Izuma, \& Matsumoto, 2010). Thus, if outcomes beyond task performance are considered, all "rewards" (and sources of enhanced expectations) may not be equal. Further, as the autonomy studies suggest, there are now a more substantial set of findings in which choice, perceived control, and other forms of autonomy support produce superior performance and/or learning than do control or yoked conditions without choice (see also Murayama, Matsumoto, Izuma, Sugiura, Ryan, Deci et al., 2015; Patall, Cooper, \& Robinson, 2008).

However, the undermining effect of extrinsic rewards is not universal (Eisenberger, Pierce, and Cameron, 1999; Lutz, Pedroni, Nadig, Luechinger, \& Jäncke, 2012; Marsden, Ma, Deci, Ryan, \& Chiu, 2015). An additive impact of external rewards and intrinsic motivation on performance and free choice behavior can occur when rewards follow performance standards that require higher levels of attention, effort, and performance, and thus perhaps assist in the development of greater perceived competence. Additive effects of the "reward" of expectancies enhanced with positive social comparison and autonomy support (Wulf, Chiviacowsky, \& Cardozo, 2014), and of enhanced expectancies due to liberal definitions of success with autonomy support (Chiviacowsky, Wulf, \& Lewthwaite, 2012) have also been found in motor learning. The differentiation of effects of different forms of motivation affecting enhanced expectancies is likely a fruitful target in the near term for neuroscientific study.

\section{External focus of attention}

Attention may refer to task and environment monitoring, scope or breadth of physical and other cues relevant to task performance, the skill or ability to control concentration despite conflicting inputs or distraction, as well as concentration on content regarding particular movement-relevant cues. We address the latter aspect of the attentional literature-what learners should focus on to optimize learning. Experimental evidence has amassed for the benefits of adopting an external focus on the intended movement effect (e.g., on an implement) relative to an internal focus on body movements (for reviews, see Lohse, Wulf, \& Lewthwaite, 2012; Marchant, 2011; Wulf, 2007a, 2013). Since the publication of the first study demonstrating the advantages of an external focus for motor learning (Wulf, Höß, \& Prinz, 1998), many studies have followed. In that original study, balance learning was found to be enhanced when participants in an external focus group were instructed to focus on the pressure exerted on the wheels of a skisimulator (Experiment 1) or the markers attached to a balance platform (Experiment 2) as opposed to their feet (internal focus groups). What is particularly striking is that, in these and subsequent studies, a one- or two-word difference in the instructions ("your feet" vs. "the markers") had differential effects on learning. That is, instructions directing attention away from one's body parts or self and to the intended movement effect have consistently been found to have an enhancing effect on performance and learning - despite the similar information content. The use of analogies may serve the same purpose by directing attention to the production of a given image (i.e., external focus), rather than body movements (Liao \& Masters, 2001; Wulf \& Toole, 1999).

A person's attentional focus often has a similar influence on performance during the practice phase when focus instructions are given, and learning, as measured by retention or transfer tests. Therefore, a number of studies have used within-participant designs to examine immediate effects of different attentional foci on performance. In either case, enhanced performance or learning with an external relative to an internal focus has been found for various measures of movement effectiveness (e.g., accuracy in hitting a target, producing a certain amount of force, maintaining a balance position) and efficiency (e.g., reduced muscular activity, oxygen consumption, heart rate). As skilled performance is characterized by both high levels of movement effectiveness and efficiency (Guthrie, 1952), those findings provide evidence that an external focus of attention effectively speeds the learning process so that a higher skill level is achieved sooner (Wulf, 2007a). Also, when learners adopt an external as opposed to an internal focus, movement kinematics start to resemble those typically seen at later stages of learning.

\section{Movement effectiveness}

\section{Balance}

A number of studies have used balance tasks to assess performance and learning differences as a function of an external versus internal focus. Balance has been shown to be enhanced when the performer's attention is directed externally to minimizing movements of a balance platform (or markers attached to it) as compared to being directed internally to movements of their feet (Chiviacowsky, Wulf, \& Wally, 2010; Jackson \& Holmes, 2011; McNevin, Shea, \& Wulf, 2003; Shea \& Wulf, 1999; Wulf, Weigelt, Poulter, \& McNevin, 2003). Other tasks have included standing still on other movable platforms (Laufer, Rotem-Lehrer, Ronen, Khayutin, \& Rozenberg, 2007; Rotem-Lehrer \& Laufer, 2007) or an inflated rubber disk (Wulf, Landers, Lewthwaite, \& Töllner, 2009), or riding a Pedalo (Totsika \& Wulf, 2003). An external focus has also been shown to yield more effective responses to perturbations (Ducharme \& Wu, 2015). When control conditions without focus instructions were included (Landers, Wulf, Wallmann, \& Guadagnoli, 2005; Wulf et al., 1998, Experiment 1; Wulf, Weigelt, Poulter, \& McNevin, 2003, Experiment 2; Wulf, 
Landers, Lewthwaite, \& Töllner, 2009), they yielded similar performances as internal focus instructions, and both led to inferior outcomes relative to external focus instructions.

\section{Accuracy}

Movement effectiveness as a function of attentional focus has also been assessed by using outcome measures such as the accuracy in hitting a target. Accuracy in hitting golf balls has been demonstrated to be enhanced when performers were asked to focus externally on the club motion or intended ball trajectory (Bell \& Hardy, 2009; Wulf \& Su, 2007) rather than on their arms (Wulf \& Su) or wrists (Bell \& Hardy). Accuracy in throwing balls (Al-Abood, Bennett, Hernandez, Ashford, \& Davids, 2002; Chiviacowsky, Wulf, \& Ávila, 2013; Zachry et al., 2005), darts (Lohse, Sherwood, \& Healy, 2010; Marchant, Clough, \& Crawshaw, 2007), or Frisbees (Ong, Bowcock, \& Hodges, 2010) also has been found to be improved with an external focus.

In other studies, participants were asked to produce a certain amount of force while concentrating on the effector, such as the hand, tongue (Freedman, Maas, Caligiuri, Wulf, \& Robin, 2007) or foot (Lohse, 2012; Lohse, Sherwood, \& Healy, 2011), or on the device against which the force was exerted, such as a bulb or platform. For example, Lohse trained participants to produce a certain percentage of their maximum voluntary contraction (MVC) in a plantar flexion task. Participants trained under the external focus condition (focus on platform) were significantly more accurate by the end of practice and on retention and transfer tests one week later than the internal focus group (focus on foot).

\section{Movement efficiency}

A movement pattern is considered more efficient or economical if the same movement outcome is achieved with less energy expended. Direct measures of efficiency that have been used in examinations of attentional focus effects include muscular (electromyographic or EMG) activity, oxygen consumption, and heart rate. In other studies, more indirect measures such as maximum force production, movement speed, or endurance were used.

\section{Muscular activity}

EMG activity has been measured in studies using targetoriented tasks such as free throw shooting in basketball (Zachry et al., 2005) and dart throwing (Lohse, Sherwood, \& Healy, 2010). For example, in a study by Lohse et al., an external focus on the flight of the dart not only improved throwing accuracy relative to a focus on the hand, but also resulted in reduced EMG activity in the antagonist triceps muscle. Similar findings were obtained in a study by Zachry et al.'s for basketball free throw shooting. These studies are interesting as they demonstrate a possible association between muscular activity and movement accuracy. It is also noteworthy that EMG activity was affected in muscle groups that participants were not specifically instructed to focus ondemonstrating that a performer's attentional focus on one part of the body can "spread" to other muscle groups, thus increasing movement inefficiency at a more general level (see also Wulf, Dufek, Lozano, \& Pettigrew, 2010; Vance et al., 2004).

EMG activity has also been found to be lower when performers were asked to focus on the weight they were lifting as opposed to their arms or legs with which they were lifting the weight, or in control conditions (Marchant, Greig, \& Scott, 2008; Vance, Wulf, Töllner, McNevin, \& Mercer, 2004). Lohse, Healy, and Sherwood (2011) found fewer co-contractions of agonist and antagonist muscles with an external relative to an internal focus on an isometric force production task, in addition to more accurate force production (Figure 5) (see also Lohse \& Sherwood, 2012). Furthermore, an analysis of the power spectral density of the EMG signal in the Lohse et al. (2011) study demonstrated increases in the median power frequency - indicating superfluous motor unit recruitment of larger motor units within the muscles - when participants focused internally.

\section{Maximum force production}

Producing maximum forces requires optimal coordination among and within muscles. Studies have demonstrated greater maximum force production with an external relative to an internal focus or control conditions, including tasks involving isokinetic contractions (Marchant, Greig, \& Scott, 2009), maximum vertical jump height (Wulf \& Dufek, 2009; Wulf, Zachry, Granados, \& Dufek, 2007; Wulf, Dufek, Lozano, \& Pettigrew, 2010), standing long-jump (Porter, Anton, \& Wu, 2012; Porter, Ostrowski, Nolan, \& Wu, 2010; Wu, Porter, \& Brown, 2012), or discus throwing (Zarghami, Saemi, \& Fathi, 2012) (for a review, see Marchant, 2011). Interestingly, the production of greater maximal forces with an external focus also has been found to be associated with reduced muscular activity (Marchant et al., 2009b; Wulf \& Dufek, 2009; Wulf, Dufek, Lozano, \& Pettigrew, 2010).

\section{Speed and endurance}

Enhanced movement efficiency with an external focus is also reflected in greater movement speed and endurance. For instance, faster running times for an agility task (Porter, Nolan, Ostrowski, \& Wulf, 2010) or sprint starts (Ille, Selin, Do, \& Thon, 2013) were seen when participants adopted an external focus (e.g., clawing the floor with the shoes), compared with an internal focus (i.e., moving the legs and feet down and back as quickly as possible). Also, oxygen consumption was reduced in experienced runners when they focused externally (Schücker, 


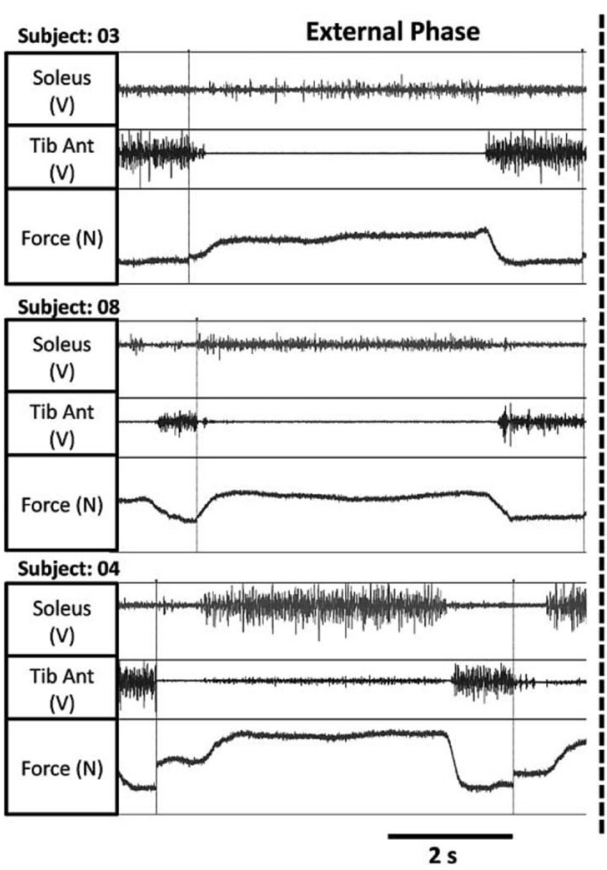

Fig. 5 EMG and force data of 3 representative participants from the study by Lohse et al. (2011). The task involved pushing against a force platform with the foot and producing $30 \%$ of the maximal force. Focusing externally on the platform versus internally on the muscle (soleus) producing the force led to very different results. Agonist and antagonist

Hagemann, Strauss, \& Völker, 2009; Schücker, Anheier, Hagemann, Strauss, \& Völker, 2013). Similarly, swim times were reduced in novices (Freudenheim, Wulf, Madureira, \& Corrêa, 2010) and experts (Stoate \& Wulf, 2011) when they focused on pushing the water back as opposed to pulling their hands back. Marchant, Greig, Bullough, and Hitchen (2011) demonstrated the benefits of an external focus on muscular endurance (i.e., increased number of repetitions) in trained individuals performing various weight lifting tasks. Finally, Neumann and Brown (2013) gave different attentional focus instructions to participants performing sit-ups. External focus instructions resulted in reduced heart rate and EMG activity than internal focus instructions, despite a larger range of motion.

\section{Movement form}

Aside from enhanced coordination within muscles (i.e., motor unit recruitment) and between muscles (i.e., co-contractions), there is accumulating evidence that an external focus also facilitates coordination on a larger scale. Expert ratings (Abdollahipour, Wulf, Psotta, \& Palomo Nieto, 2015; Wulf, Chiviacowsky, Schiller, \& Ávila, 2010) as well as analyses of movement kinematics (An, Wulf, \& Kim, 2013; Christina \& Alpenfels, 2014; Lohse, Sherwood, \& Healy, 2010; Parr \& Button, 2009; Southard, 2011; Wulf \& Dufek, 2009) have shown that movement form can be optimized with external relative to an internal focus as well. For example, in novice rowers, instructions directed at the blade (e.g., "Keep the

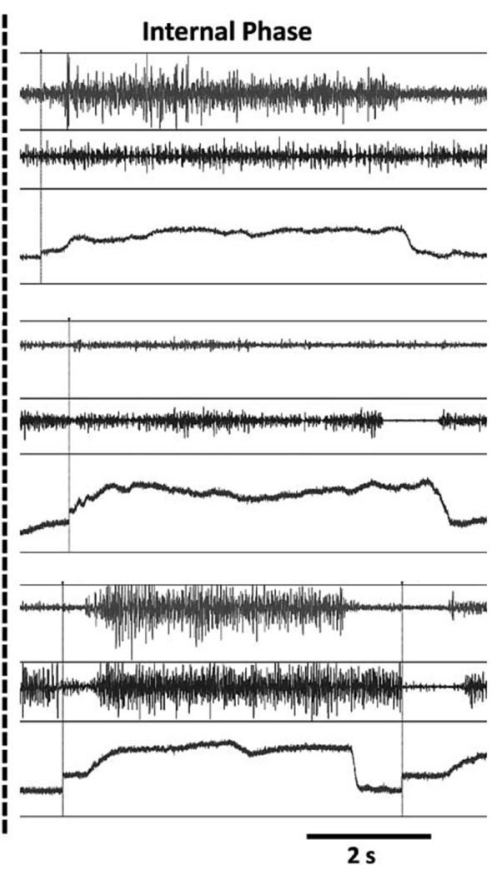

activity was reduced and force production was more accurate with an external focus. Note. From "Neuromuscular effects of shifting the focus of attention in a simple force production task," by Lohse, Sherwood, and Healy, 2011, Journal of Motor Behavior, 43, p. 178

blade level during the recovery") rather than the hands (e.g., "Keep your hands level during the recovery") led to greater improvements in the technique, as evidenced by various kinematic measures after a 7-week retention interval (Parr \& Button). Another study examined the effects of attentional focus instructions on the learning of movement form in novice golfers (An et al.). The instructions were aimed at increasing the angle between the shoulders and pelvis during the downswing - a characteristic of skilled performance - that can be achieved by encouraging a forward weight shift. External focus instructions to "push against the left side of the ground" (for right-handed participants) resulted in a greater increase in that angle than did internal focus instructions to shift their weight to the left foot, or no instructions (control group). Importantly, the carry distance of the ball was increased by the external focus instructions as well (Figure 6). Thus, a single external focus instruction enhanced both movement form and outcome in novices. A similar pattern of results was found for experienced gymnasts (Abdollahipour et al.) who performed a gymnastics skill (180-degree turn in the air). Movement form (number of deductions) as well as movement outcome (jump height) were enhanced by one instruction that promoted an external focus. Finally, Christina and Alpenfels showed that experienced golfers learned to change their swing path more effectively with external rather than internal focus instructions. Overall, it is clear that the performer's attentional focus fundamentally 


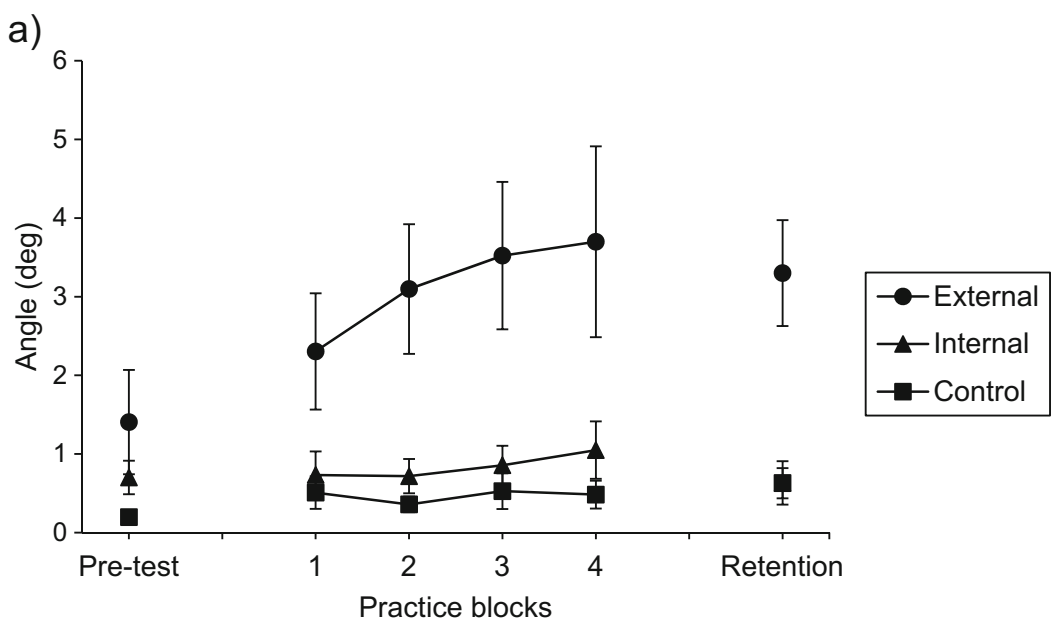

b)

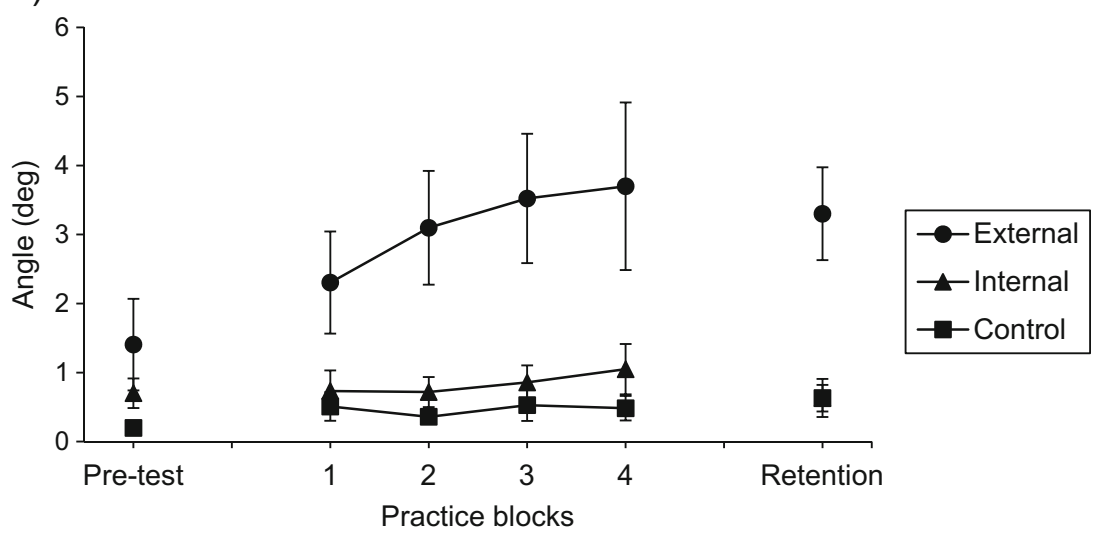

Fig. 6 Results of the study by An et al. (2013) in which different groups of novice golfers hit golf balls under external focus, internal focus, or control conditions (see text for more details). The pre-test and retention test (after 3 days) included 10 trials, whereas the practice blocks included 25 trials each. The increase in the angle between shoulders and pelvis

affects movement coordination. An external focus on the intended movement effect enhances all aspects of performance, independent of skill level, task, age, or (dis)ability.

\section{External focus promotes automaticity}

The attentional focus effect has been explained with the constrained action hypothesis (Wulf, McNevin, \& Shea, 2001; Wulf, Shea, \& Park, 2001), according to which an internal focus induces a conscious type of control - causing individuals to constrain their motor system by interfering with automatic control processes. In contrast, an external focus promotes a more automatic mode of control by utilizing unconscious, fast, and reflexive control processes. Several converging lines of research support this notion. Evidence suggests that an internal focus indeed leads to a constrained motor system, or "freezing" of degrees of freedom (Vereijken, van Emmerik, Whiting, \& Newell, 1992), whereas an external focus seems to "free" those degrees of freedom. Evidence includes correlations between joint movements (Ford, Hodges, Huys, \& during the downswing as well as the carry distance of the ball were greatest in the external focus group. Note. From "Increased carry distance and X-factor stretch in golf through an external focus of attention," by J. An, G. Wulf, and S. Kim, 2013, Journal of Motor Learning and Development, 1, p. 6

Williams, 2009) or joint moments (Wulf \& Dufek, 2009) with an internal but not external focus. An external focus on the intended movement effect also appears to increase "functional variability" (Loosch, 1995), which is typically seen in skilled performers (e.g., dart throwers; Müller \& Loosch, 1999). In essence, it reflects compensatory corrections among various effectors, with the results that variability in the movement outcome is decreased. For example, in skilled dart players it was observed that smaller release angles were compensated by higher velocities of the dart, and vice versa (Loosch, 1995; Wulf \& Prinz, 2001). Lohse and colleagues (Lohse, Jones, Healy, \& Sherwood, 2014; Lohse, Sherwood, \& Healy, 2010) demonstrated that an external focus also leads to greater functional variability than an internal focus.

Studies also have shown an association of external focus instructions and various measures of automaticity. For example, the attentional demands of the task have been shown to be reduced when performers adopt an external rather than internal focus (Kal, van der Kamp, and Houdijk, 2013; Wulf, McNevin, \& Shea, 2001). Using a probe reaction time paradigm, Wulf 
et al. found short reaction times with an external focus on a balance task. Enhanced performance on a secondary task (i.e., faster reaction times) indicated reduced attention demands - or greater automaticity — of the primary task. Probe reaction times generally decreased across practice, indicating that attentional demands decreased with experience. Importantly, shorter reaction times for the external relative to the internal focus group corroborated the view that an external focus speeds the learning process by facilitating automaticity. Providing further support for this notion, Kal et al. more recently demonstrated reduced cognitive dual-task costs with an external relative to an internal focus. Using a cyclic leg extension-flexion task, Kal et al. also measured movement fluency (i.e., jerk) as well as movement regularity (i.e., sample entropy) under external and internal focus conditions. Both fluency and regularity were enhanced with an external focus, providing further evidence for greater automaticity when an external focus is adopted.

In another line of evidence, analyses of the movement frequency characteristics, particularly in balancing, have shown higher-frequency movement adjustments for external compared to internal focus participants (McNevin et al., 2003; Wulf, McNevin et al., 2001; Wulf, Shea, \& Park, 2001). Higher frequencies are viewed as an indication of a more automatic, reflex-type mode of control. This suggests that learners who concentrated on markers on the balance platform (external focus) utilized more, and faster, reflex loops operating at an automatic level, while those who focused internally on their feet used more conscious, and slower, feedback loops. Interestingly, placing the markers at a greater distance from the feet resulted in even higher frequencies in responding, as well as greater stability, than focusing on markers directly in front of the feet (McNevin, Shea, \& Wulf, 2003). This suggested that movement effects that occur at a greater distance from the body, or self - and are presumably more easily distinguishable from body movements - result in even greater automaticity. This "distance" effect has been replicated with other tasks, including hitting golf balls (Bell \& Hardy, 2009), dart throwing (McKay \& Wulf, 2012), or the standing long jump (Porter, Anton, \& Wu, 2012).

\section{Other lines of attentional focus research}

A number of interventions, beyond an external focus instructional approach, have been developed in recent years that may broadly be seen as aimed at providing the motor learner with a beneficial attentional focus. Some of the more notable ones include implicit learning (Masters \& Poolton, 2012), the quiet eye (Vickers, 1996), mindfulness training (Kee, Chatzisarantis, Kong, Chow, \& Chen, 2012), and self-talk (Chang et al., 2014; Hardy, Begley, \& Blanchfield, 2015). We outline some commonalities and differences between the assumptions underlying those approaches and the ones we have put forward in this theory.
Since the early 1990s, Masters and his colleagues have argued that movements should ideally be learned implicitly rather than explicitly (Masters, 1992; Maxwell, Masters, \& Eves, 2000). Therefore, instructions should be kept to a minimum as they increase the likelihood that learners "reinvest" acquired knowledge and engage in conscious control processes that interfere with the automatic execution of the movement. Many aspects of motor skills can be and presumably are learned implicitly, including regularities in environmental stimuli and balance skills, and it has been shown that implicit learning can be more effective than explicit learning (Green \& Flowers, 1991; Shea, Wulf, Whitacre, \& Park, 2001; Wulf \& Schmidt, 1997). Indeed, the motor system's remarkable coordination capabilities seen with an external focus of attention are presumably a reflection of the effectiveness of implicit processes (Wulf, Höß, \& Prinz, 1998). However, we question the idea that learners should generally not be given instructions about the correct movement technique. It is unlikely that knowledge per se is detrimental to performance. Rather it appears critical that an appropriate external focus be adopted in preparation for or during performance (Wulf, 2016). Thus, it is not that the entire process must be implicit or explicit, but that timely goal-action coupling is facilitated. If that coupling is effected by an overt instruction, or by the nonconscious recognition of a primed goal, both explicit and implicit conditions can facilitate goal-action binding.

In another line of research, the so-called "quiet eye"-a final visual fixation of at least $100 \mathrm{~ms}$ directed at a certain location or target (e.g., golf ball, basketball hoop, bull's eye) before movement execution - has been shown to be associated with enhanced performance of tasks with specific targets (Moore, Vine, Freeman, \& Wilson, 2013; Vickers, 1996). Whereas various possible accounts of this phenomenon have been offered (for a review, see Vickers, 2009), it seems likely that an external attentional focus promoted by the visual focus on an external object is at least partially responsible for the performance effects (Vine, Moore, Wilson, 2011, 2015). Aside from keeping the attentional focus on a relevant aspect of the task (e.g., golf ball), a visual focus on the target may also serve to "clear the performer's mind" (Vine, Moore, Wilson, 2015).

Mindfulness training may serve a similar "mind-clearing" function. Mindfulness, a state of non-judgmental awareness of the present moment (Brown \& Ryan, 2003), has been linked to reductions in stress and negative affect (Taren, Gianaros, Greco, Lindsay, Fairgrieve, Brown et al., 2015). Moreover, mindfulness training has been shown to lead to improved decision making (Hafenbrack, Kinias, \& Barsade, 2013). Mindfulness training has been related to enhanced balance performance resulting from greater automaticity in movement control (Kee et al., 2012). Interestingly, after a mindfulness induction participants also reported a greater use of an external focus of attention compared with control group participants. 
Doll and colleagues (Doll, Hölzel, Boucard, Wohlschläger, \& Sorg, 2015) found evidence that 2 weeks of mindfulness intervention focused on breath training (a component of mindfulness training) in novices of this technique was associated with increased functional connectivity between the default mode network and the salience network (see section on "Goal-action coupling: a common mechanism for motivational and attentional effects on motor performance and learning"). How this pattern of increased connectivity might relate to other components of mindfulness training and especially to motor task performance will be important areas for future research, and may distinguish this form of intervention for motor performance and skill acquisition from external attentional focus instructions with movement effect focus. Wilson and colleagues recently identified a potential unintended consequence of mindfulness meditation-increased susceptibility to false memories, possibly suggesting that attention to some task-relevant foci could be impaired (Wilson, Mickes, Stolarz-Fantino, Evrard, \& Fantino, 2015). Thus, clearing the mind from distracting or self-related thoughts may be helpful, but an affirmative external focus on relevant movement effects may potentially be even more beneficial.

Self-talk training has been used to assist athletes in systematizing their internal dialogues before performance. Content of such self-talk regimen are often categorized as motivational versus instructional or informational in nature, although there are wide variations in the specific focus and wording of self-talk statements. Hardy and colleagues found that skilled Gaelic football players attempting free kicks with their dominant and nondominant feet performed with greater kicking accuracy with a motivational self-talk statement (dominant limb) and equally well with motivational or instructional self-talk using their nondominant foot (Hardy et al., 2015). Chang and colleagues examined novice high school students performing a softball throw for accuracy and distance, and motivational, instructional, and unrelated (weather, pet's and parents' names, etc.) self-talk conditions (Chang et al., 2014). Motivational self-talk was confidencedirected in nature ("I can do it, I believe I can do it well," etc.). Instructional self-talk was a mixture of internal and external attentional foci. Throwing for accuracy was better for both motivational and instructional self-talk relative to unrelated self-talk, and best for motivational self-talk when the task was throwing for distance. Self-efficacy was enhanced in parallel with performance results. Self-talk research has often incorporated self-efficacy theory but generally not benefited by integration with the work on attentional focus described previously (although Hardy et al., 2015 is an exception). Efforts to consider how to facilitate goal-action coupling from positive motivational and external attentional approaches might optimize performers' results.

\section{Interim summary: attentional focus}

Directing performers' attention to the (environmental) effects of their movements (external focus), rather than to the coordination of their body movements per se (internal focus), results in more effective performance and learning. By facilitating automaticity in movement control, an external focus generally results in more effective performance (e.g., movement accuracy, balance, maximum force production) than does a counterpart internal focus. Moreover, the enhanced outcome is achieved with less effort, as indicated by reduced muscular activity, heart rate, oxygen consumption, and so forth. Thus, movement efficiency is enhanced as well. An external focus of attention seems to be a precondition for optimal motor performance. Interestingly, interviews have shown that, even without explicit internal focus instructions, learners tend to focus on movement form and body movements (Pascua, Wulf, and Lewthwaite, 2015). This includes athletes (GussWest \& Wulf, 2016; Porter, Wu, \& Partridge, 2010; Stoate et al., 2012). The reliability of the external focus benefits across tasks, skill levels, age groups, or other individual differences (Wulf 2007a, 2013) suggests that the necessity of focusing on the intended movement effect to achieve successful outcomes reflects a fundamental movement principle.

\section{Mechanisms for attentional focus effects}

Why is an external focus integral to optimal motor performance? We suggest that an external relative to an internal focus plays a dual role by (a) directing attention to the task goal and (b) reducing a focus on the self. Thus, an external focus is an important contributor to goal-action coupling (Figure 3). Furthermore, by reliably producing more successful performance outcomes and ease of movement as noted above, an external attentional focus contributes to enhanced expectancies for positive outcomes (Pascua, Wulf, and Lewthwaite, 2015; Shafizadeh, Platt, \& Bahram, 2013; Wulf, Chiviacowsky, \& Cardozo, 2014) through mechanisms described in earlier sections. In Figure 3, this influence is represented by the arrow going from (improved) motor performance to enhanced expectancies.

The ecological importance of an external focus can be illustrated by this example: What does the mountain goat about to jump across a chasm focus on? Presumably, it focuses on the other side of the chasm to which it is jumping. Its motor system seems to "know" what it has to do to achieve the desired outcome. A skilled and confident human in a similar situation might also let his or her motor system do its job and successfully land on the intended spot. An external attentional focus may be the intrinsic, "natural," or default focus to movement skills from which humans tend to stray over time - perhaps "aided" by well-intended teaching or coaching, and 
thoughts and ideas about the best ways to produce valued movement. It is hard to imagine other animals moving affirmatively for food or survival with a constant internal conversation regarding how to move their limbs most effectively. Likely, they pursue their goals with purpose and action unimpaired by digressions into self-reflection or concerns about how to coordinate their muscles and joints.

One advantage of adopting a focus on the intended outcome (e.g., landing location) may be that it directs concentration to the intended movement effect or task goal. Indeed, a recent study by Russell, Porter, and Campbell (2014) showed nicely that an external focus on the primary task (dart throwing) was necessary to enhance performance, whereas an external focus on a simultaneously performed secondary task - which should have directed attention away from the self-was not able to enhance performance (similar to internal foci on either task). The consequence of focusing on the intended effect is a coordination pattern that resembles one that is typically seen at a more advanced skill level -with a more efficient recruitment of motor units, fewer co-contraction of agonists and antagonists (Lohse \& Sherwood, 2012), greater force output (Marchant, Greig, \& Scott, 2009), a "freeing" of the body's degrees of freedom (Wulf \& Dufek, 2009; Wulf, 2013), increased functional variability (Lohse et al., 2014; Wulf \& Prinz, 2001), and generally increased movement accuracy. How exactly the motor system accomplishes this is perhaps one of most intriguing questions.

We have previously proposed the notion of a "self-invoking trigger" (McKay, Wulf, Lewthwaite, \& Nordin, 2015; Wulf \& Lewthwaite, 2010). According to this view, instructions that promote an internal focus by referring to body movements provoke access to the self and result in "microchoking" episodes (Wulf \& Lewthwaite, 2010), that is, widespread, inefficient activation of the muscular system, disruption of automaticity, and the use of more conscious control over ongoing movement. The result is a constrained movement pattern which can be seen when a player "short-arms" a free throw in basketball or when a golfer leaves a putt short. While the self-invoking trigger idea is still somewhat speculative, a study by McKay et al. (2015) provided initial evidence consistent with this notion. In two experiments, asking performers to reflect on their task-related experience resulted in degraded performance (Experiment 1) or learning (Experiment 2) relative to the control condition (Figure 7). A study by Perreault and French (2015) provides additional preliminary evidence for the self-invoking trigger hypothesis. Children between the ages of 9 and 11 years practiced basketball free-throws and were given internal- or external-focus feedback. In response to the question about what they were thinking at the conclusion of the experiment, those in the internal focus group reported more self-evaluative content (36-57\%) than did participants in the external focus group

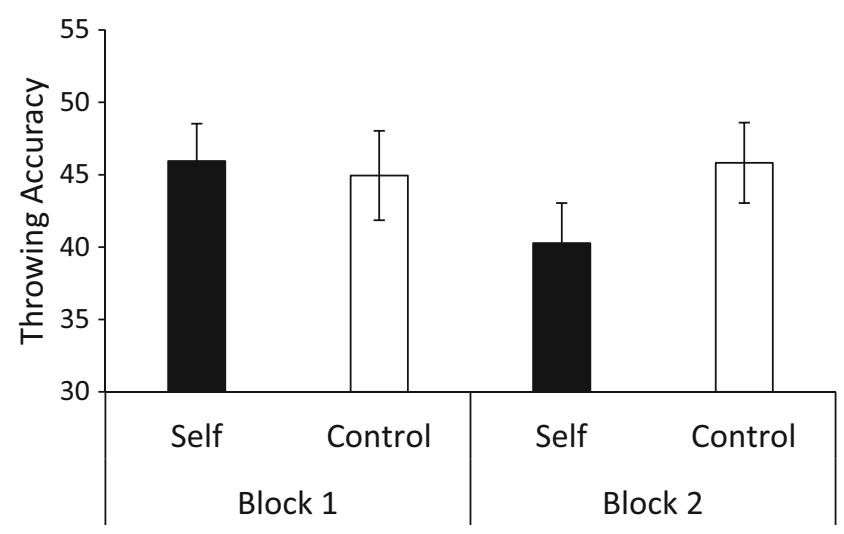

Fig. 7 Throwing accuracy (higher scores reflect greater accuracy) of self and control groups. Between 2 blocks of 10 throws, participants in the self group were to asked think about their previous throwing experience including their strengths and weaknesses as a thrower. As a result, throwing accuracy was degraded on block 2, whereas that of a control group remained unchanged. Note. From "The self: Your own worst enemy? A test of the self-invoking trigger hypothesis," by McKay, Wulf, Lewthwaite, and Nordin, 2015, Quarterly Journal of Experimental Psychology, p. 1913

(7-21\%). One advantage of adopting an external focus on the intended outcome may be that it directs concentration away from the self.

Self-referential processing appears to be a significant aspect of the brain's default mode of operation (Brewer, Worhunskya, Gray, Tang, Weber, \& Kober, 2011; Buckner, Andrews-Hanna, \& Schacter, 2008). Brain imaging studies have revealed the importance of the self in humans and how easily it is accessed. Self-referential processing has been shown to occur in brain structures at the cortical midline, in particular the medial prefrontal cortex (mPFC) (Amodio \& Frith, 2006; Eisenberger, Lieberman, \& Satpute, 2005; for a review, see Northoff et al., 2006). The mPFC seems to be linked to a variety of self-related capacities that are maintained across space and time, reflecting the self (Gallagher, 2000). This includes the recognition of one's physical characteristics (Sugiura, Watanabe, Maeda, Matsue, Fukuda, \& Kawashima, 2005), memory for one's personality traits (Craik, Moroz, Moscovitch, Stuss, Winocur, Tulving, et al., 1999), or one's hopes for the future (Johnson et al., 2006). Also, a temporary association of self and objects that were assigned to participants, for example, engaged the mPFC more than other objects (Kim \& Johnson, 2012). Even word processing while reading (without instructions for self-referential processing) has been found to be different depending on whether the word is preceded by a personal pronoun ("my") instead of an article ("the")- particularly when the noun is unpleasant (Herbert, Pauli, \& Herbert, 2011). These findings highlight the importance of the self for human beings (James, 1890) - and how easily it can be activated. 


\section{Goal-action coupling: a common mechanism for motivational and attentional effects on motor performance and learning}

Insight into brain systems subserving self-referential processing may provide one key to the mechanisms by which attentional focus and motivation can produce performance and learning effects. Motor learning is associated with structural changes in neuroanatomy as well as in functional connections across brain regions. We posit that practice under optimal motivational and attentional focus conditions facilitates the development of more effective neural connections in support of better performance and more efficient learning. Both enhanced expectancies (and related autonomy) and attentional focus direct movers with relative clarity toward their action goals. Furthermore, these drivers may suppress off-task and self-focused attention, buffering learners from these obstacles to optimal performance (McKiernan, Kaufman, KuceraThompson, \& Binder, 2003). Figure 3 illustrates the putative model for enhanced expectancy, autonomy, and external focus effects on performance and learning.

Structural connections within brain regions concern gray and white matter and more localized projections and pathways that develop through practice and use (Dayan \& Cohen, 2011; Draganski \& May, 2008). Beyond the motivational potentiation of learning attempts described in earlier sections, dopamine influences synaptogenic processes that create more robust connections, including long-term potentiation at the cellular level (Ashby et al., 1999; Shohamy \& Adcock, 2010; Wise, 2004) and enlargement of the spiny processes on medium spiny neurons to facilitate new neural connections (Yagishita, Hayashi-Takagi, Ellis-Davies, Urakubo, Ishii, \& Kasai, 2014). Dopamine, in its motivational role, also contributes to the consolidation of motor memories when present during and after motor practice (Sugawara, Tanaka, Okazaki, Watanabe, Sadato, 2012; Wise, 2004).

Functional connectivity refers to temporal linkages between spatially distinct neural regions or networks, including large-scale coordinated activations and deactivations of various structures and subsystems, that occur relative to task (or non-task) performance and learning (Di \& Biswal, 2015; Friston, 2011; Fox et al., 2005). Correlated low-level oscillatory resonance of activity patterns in participating regions can be observed at rest when regions have operated in concert. Reward-related dopamine boosts the replay or reactivation of memories during rest that contribute to consolidation (Ewell \& Leutgeb, 2014). It has been argued that the strength of the functional connectivity in resting-state networks reflects a history of task-relevant coactivation, with stronger coherence in spontaneous activity at rest for regions that were coactivated or fired together during the task (Corbetta, 2012).
The default mode network is a key functional network, centering brain activity, and pertaining to cognition, including diverse functions such as long-term planning, mind wandering, and self-referential thought (Buckner, 2012; Buckner, et al., 2008; Gusnard, Akbudak, Shulman, \& Raichle, 2001). As its name implies, the default mode network is spontaneously active when other systems are passive, although it does not always deactivate when other so-called task-positive or attentional networks are active (Raichle, 2015). The default mode network roughly includes the ventral medial prefrontal cortex, the dorsal medial prefrontal cortex; and the posterior cingulate cortex, precuneus, and lateral parietal cortex (Raichle, 2015).

The default mode network typically does not overlap with functional groupings involved in goal-directed and motor tasks. A number of other functionally organized networks have been identified, with some overlap in regions various researchers have included within each. These networks include: a dorsal attention network, a central executive network, task-positive networks, a sensorimotor network, a reward network, and a salience network. Clusters of brain regions involved in motor learning can be recognized, both at rest (Albert, Robertson, \& Miall, 2009; Biswal, Yetkin, Haughton, \& Hyde, 1995; Wu, Srinivasan, Kaur, \& Cramer, 2014) and in-task (Hasan et al., 2013).

Functional connectivity can be disrupted in a number of diseases and disorders, including clinical conditions such as Parkinson's disease, traumatic brain injury, depression, Alzheimer's disease, autism, schizophrenia, and stroke (Buckner, Andrews-Hanna, \& Schacter, 2008; Corbetta, 2012). Importantly, functional connectivity is related to motor skill learning (Albert et al., 2009; Song, Gotts, Dayan, \& Cohen, 2015) and to higher levels of motor skill (Di, Zhu, Jin, Wang, Ye, Zhou et al., 2012; Ito, Matsuda, \& Shimojo, 2015; Kim, Han, Kim, \& Han, 2015; Milton, Solodkin, Hluštík, \& Small, 2007; Li, He, Huang, Zhang, Lu, Lai et al., 2015). Functional connectivity tracks the learning of motor skills, and more distinct functional connections are associated with higher skill (Kim, Chang, Kim, Seo, Ryu, Lee et al., 2014; Milton et al., 2007).

Shifting from default mode to other task-related functional networks to accomplish different activities may be challenged in conditions such as Parkinson disease (Delaveau et al., 2010; van Eimeren, Monchi, Ballanger, \& Strafella, 2009) and depression (Greicius, Flores, Menon, Glover, Solvason, Kenna et al., 2007). The salience network comprises cortical (anterior insula and dorsal anterior cingulate cortex) and subcortical (amygdala, ventral striatum, including nucleus accumbens, and substantia nigra/ventral tegmental area) regions with diverse roles in detecting events salient to the organism, and integrating cognitive, emotional, motivational, motor, and interoceptive signals into response selection (Floresco, 2015; Menon, 2015; Sridharan, Levitin, \& Menon, 2008). The salience network has recently been identified as critical in executing the switch between networks focused on exogenous and self-referential processing to 
reposition the organism for new tasks (Sridharan et al., 2008). The salience network, with its integrative nature and networkswitching role, may be an important site for future investigations into goal-action coupling by positive motivation and external attentional focus.

\section{Conclusions and predictions}

While it may seem deceptively simple and almost automatic, expert performers find ways to will efficient and sometimes spectacular movements into being. How do they learn to cut to the chase and connect their thoughts to their actions? We have reviewed several lines of evidence that document the impacts of positive motivational and attentional focus variables on motor performance and learning. Conditions that enhance expectancies for future performance success, including potential satisfaction of the psychological need for competence are important. Circumstances that provide an opportunity for choice or self-determination, even minimally, influence learners' sense of agency or autonomy, with consistently beneficial results. Instructions or feedback that promote an external focus of attention by directing concentration to a relevant and appropriate external goal are reliably more helpful than internal attention focused on body parts or movement coordination. Table 1 identifies a number of predictions that follow from the OPTIMAL theory.

We contend that these factors contribute to successful outcomes by strengthening the coupling of performers' goals to their movement actions, presumably operating in complementary ways. We provide a plausible mechanism for the diverse effects of expectation of positive experiences or outcomes as defined by the mover; these expectations stimulate a dopaminergic response. When this dopaminergic response is temporally linked with performance attempts, we propose that motor performance is optimized - for that learner at that given time and level of task experience (Prediction 1; Table 1). It is likely that enhanced expectancies for success will influence the facility with which a beneficial task focus can be identified and held in concentration. Enhanced expectancies as well as autonomy-supportive conditions contribute to efficient goalaction coupling by preparing the motor system for task execution (Prediction 2). Furthermore, we suggest that autonomy or learner control over some practice elements triggers a sense of agency and thus acts through enhanced expectancies to affect learning (Prediction 3).

An external focus of attention is a critical element in the coupling of goals and actions, whereas an internal focus directs attention to the self, thereby degrading performance (Predictions 4 and 5). We consider the influence of an unambiguous attentional focus on the movement goal to be a useful pairing with a sense of confidence. Furthermore, the
Table 1 Predictions of the OPTIMAL Theory

1. When temporally associated with skill practice, conditions that enhance expectancies for positive outcomes trigger dopaminergic responses and thereby benefit motor performance

2. Enhanced expectancies and autonomy support contribute to efficient goal-action coupling by readying the motor system for task execution

3. Autonomy support facilitates performance by enhancing expectancies

4. An external focus of attention directs attention to the task goal, enhancing goal-action coupling

5. An internal focus of attention impedes performance by directing attention to the self

6. Movement success resulting from an external focus enhances expectancies for future success

7. Enhanced expectancies and autonomy support facilitate motor learning by making dopamine available for memory consolidation and neural pathway development

8. Challenge, in the context of prevailing success, elicits a potentiating dopaminergic response that contributes to learning beyond success or challenge alone.

9. Higher expectancies facilitate efficient switching from the default mode network to motor networks associated with the movement skill

10. An external attentional focus facilitates efficient switching from the default mode network to relevant motor networks

11. An internal attentional focus impedes efficient switching from the default mode network to motor networks associated with the movement skill

12. Generally, conditions that optimize performance facilitate learning

advantage of an external attentional focus will be manifest in increasingly successful motor performance, thus fueling a strong sense of performance accomplishment and the expectation for more of the same (i.e., relatively high self-efficacy) (Prediction 6).

Practice conditions that create positive motivation by enhancing performers' expectancies or providing autonomy support facilitate motor learning by making dopamine available for online and offline memory consolidation and neuroplastic changes, such as structural and functional connectivity (Prediction 7). In particular, substantial success and moderately challenging practice provide the conditions for the potentiation as well as ongoing presence of dopamine, applied at the moments of successive actions (Prediction 8). Effective structural connections within brain regions would appear to lay the groundwork for the establishment of efficient functional connections across brain networks. Such connectivity appears to be a hallmark of experienced and expert performers (Di et al., 2012; Ito et al., 2015; Kim et al., 2015; Kim et al., 2014; Li et al., 2015; Milton et al., 2007).

We speculate that some of the benefits of higher expectancies and an external attentional focus occur by facilitating efficient switching within and across brain networks (Predictions 9 and 10). The proximity and connectivity of motivational and sensorimotor systems, perhaps in the salience network, make 
the delicacy of switching from the default mode network to relevant motor networks an intriguing potential locus for both beneficial and disruptive goal-action coupling. While the forté of enhanced expectancies and an external focus may be in linking goals to upcoming actions, the possibility of beneficial suppressive or preventative effects against intrusive or selffocused thoughts exists. In contrast, an internal focus would forestall switching from the default mode network to motor networks (Prediction 11). Lastly, the OPTIMAL theory predicts that, in general, conditions that optimize performance facilitate learning (Prediction 12). Paraphrasing the saying linking current success to future success, the anticipation of success breeds success and the presence of dopamine, which supports the development of skill.
As we noted in our introduction, differences between scientific fields studying motor learning from different vantage points can be challenging to overcome in order to achieve important insights. We have intrepidly walked into this intersection. Further progress will involve closing empirical gaps, including the elicitation of dopamingergic responses with a variety of "rewards" or positive experiences and capturing the process of network development and dynamic switching between networks. Testing of theory predictions will require diverse expertise. How researchers may capture exquisite network coordination and motor performance is a challenge, partially aided by resting state observations and new analytical methods and imaging technology (Di \& Biswal, 2015; O’Neill, Bauer, Woolrich, Morris, Barnes, \& Brookes,

a)

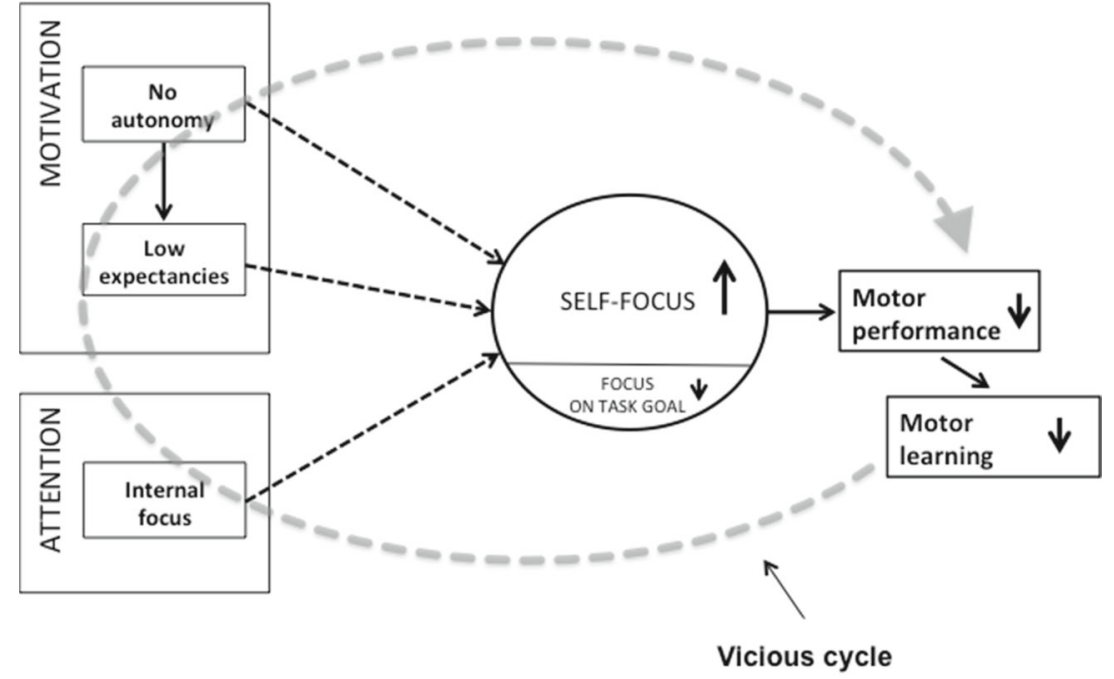

b)

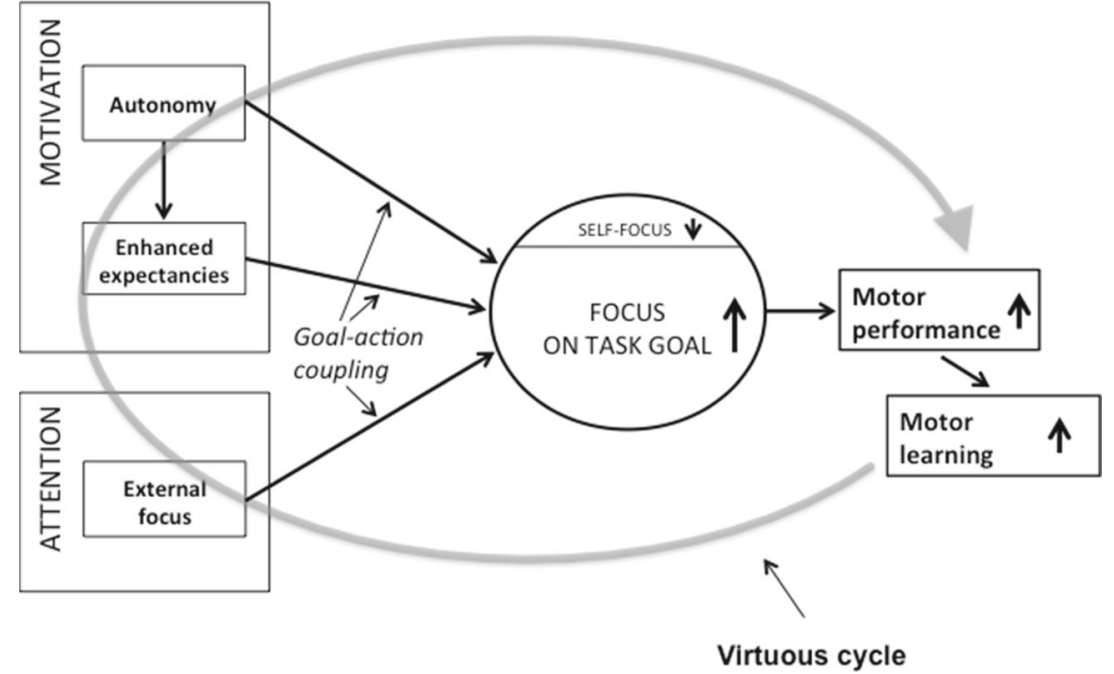

Fig. 8 Conditions that fail to enhance learners' expectancies and support their need for autonomy, and promote an internal focus of attention result in a vicious cycle of non-optimal learning (a), whereas conditions that enhance expectancies, provide autonomy support, and promote an external focus result in a virtuous cycle of enhanced motor learning (b) 
2015). Measurement of dopamine activity also is more challenging than some other biochemical substances (e.g., cortisol), because it cannot presently be assessed with salivary or other less invasive methods than positron emission technology paired with dopamine-antagonist medication (Lidstone et al., 2010). Indirect measurement may be helpful (Aarts, Bijleveld, Custers, Dogge, Deelder, Schutter et al., 2012). Furthermore, innovations in the study of moments in athletic performance are promising (Kim et al., 2015; Kim et al., 2014; Milton et al., 2007).

\section{Practical implications}

Effective and skilled movement needs permeate many areas of life, having relevance to individuals relearning basic motor control after a neurological insult, learning to drive a new vehicle, taking up or mastering a sport, controlling complex systems, handling weapons in emergency situations, learning to play a musical instrument, active gaming, using surgical instruments, operating a robotic device, mastering a new brain-computer interface or prosthesis, to name just a few. Implications of the OPTIMAL theory for optimizing motor performance and learning in applied and clinical contexts involve finding the right approaches to boosting or supporting positive motivation and directing attention to effective external foci. Instructors, teachers, coaches, trainers, and clinicians who may direct and frame learning experiences can create and make use of these performance and learning features.

In a typical scenario, the instructor (e.g., coach, physical therapist, music teacher) selects the tasks to be practiced, describes how movements should be performed, gives corrective feedback, and instructions that refer to the coordination of body movements. Observations or interviews of coaches and physical therapists confirm anecdotal evidence for the predominance of such approaches (Durham, Van Vliet, Badger, \& Sackley, 2009; Halperin, Chapman, Martin, Abbiss, \& Wulf, 2015; Johnson, Burridge, \& Demain, 2013; Porter, Wu, \& Partridge, 2010). Thus, instructors often neglect to enhance learners' expectancies, do not recognize and support their need for autonomy, and induce an internal focus of attention (Figure 8a). Direct consequences of such an approach would be low learner self-efficacy, little or no positive affect, increased self-focus, and limited capacity to focus on the task goal. Moreover, indirect consequences resulting from poor performance or little performance improvement, and learners' perceptions of effort might lead to further decreases in self-efficacy and positive affect, increased self-focus, etc. - essentially resulting in a vicious cycle and less-than-optimal learning. Ultimately, this scenario may lead to a lack of interest in practicing or learning new skills, and perhaps activity avoidance.

In contrast, imagine a scenario in which the instructor gives the learner choices, provides feedback at the request of the learner, highlights good aspects of task performance while mostly ignoring mistakes, avoids references to body movements, and instead directs the performer's attention externally to the task goal (Figure 8b). In this case, enhanced performance expectancies and perceptions of autonomy would likely increase learners' self-efficacy. [Experimentally, there have been many variations in the forms of positive motivational influences that produce performance and learning benefits. In translation, expectancies can be enhanced by intrinsic or autonomous means that do not involve external rewards, incentives, or deception, preventing threats to autonomy and social relatedness (Fenton, Duda, Quested, \& Barrett, 2014; Hagger et al., 2015).] Confidence in their ability to perform well, in combination with an instructed external focus, should facilitate successful movement outcomes. These in turn will further promote self-efficacy and positive affect that helps solidify good performance, resulting in a virtuous cycle with overall positive consequences for learning and motivation. Thus, simple changes in the wording of task instructions and feedback that are often used in applied settings (i.e., scenario 1) might be sufficient to create the conditions necessary for optimal learning.

\section{References}

Aarts, H., Bijleveld, E., Custers, R., Dogge, M., Deelder, M., Schutter, D., \& Haren, N. E. (2012). Positive priming and intentional binding: Eye-blink rate predicts reward information effects on the sense of agency. Social Neuroscience, 7, 105-112.

Aarts, H., Custers, R., \& Marien, H. (2009). Priming and authorship ascription: When nonconscious goals turn into conscious experiences of self-agency. Journal of Personality and Social Psychology, 96, 967-979.

Abdollahipour, R., Wulf, G., Psotta, R., \& Palomo Nieto, M. (2015). Performance of a gymnastics skill benefits from an external focus of attention. Journal of Sports Sciences, 33, 1807-1813.

Abe, M., Schambra, H., Wassermann, E. M., Luckenbaugh, D., Schweighofer, N., \& Cohen, L. G. (2011). Reward improves longterm retention of a motor memory through induction of offline memory gains. Current Biology, 21, 557-562. doi:10.1016/j.cub.2011.02.030

Abrams, R. A., \& Weidler, B. J. (2015). How far away is that? It depends on you: Perception accounts for the abilities of others. Journal of Experimental Psychology: Human Perception and Performance, 41, 904-908.

Al-Abood, S. A., Bennett, S. J., Hernandez, F. M., Ashford, D., \& Davids, K. (2002). Effects of verbal instructions and image size on visual search strategies in basketball free throw shooting. Journal of Sports Sciences, 20, 271-278.

Albert, N. B., Robertson, E. M., \& Miall, R. C. (2009). The resting human brain and motor learning. Current Biology, 19, 1023-1027.

Amodio, D. M., \& Frith, C. D. (2006). Meeting of minds: The medial frontal cortex and social cognition. Nature Reviews Neuroscience, 7, 268-277.

An, J., Wulf, G., \& Kim, S. (2013). Increased carry distance and X-factor stretch in golf through an external focus of attention. Journal of Motor Learning and Development, 1, 2-11.

Arias, P., Robles-García, V., Espinosa, N., Corral-Bergantiños, Y., MordilloMateos, L., Grieve, K., Cudeiro, J. (2014). The effects of expectancy on corticospinal excitability: Passively preparing to observe a movement. Journal of Neurophysiology, 111, 1479-1486. 
Ashby, F. G., Isen, A. M., \& Turken, U. (1999). A neuropsychological theory of positive affect and its influence on cognition. Psychological Review, 106, 529-550.

Ashor, A. W. (2011). The placebo effect on psychomotor performance and working memory capacity: Randomized single blind cross-over trial. Annals of Neurosciences, 18, 141-144.

Ávila, L. T. G., Chiviacowsky, S., Wulf, G., \& Lewthwaite, R. (2012). Positive social-comparative feedback enhances motor learning in children. Psychology of Sport and Exercise, 13, 849-853.

Badami, R., VaezMousavi, M., Wulf, G., \& Namazizadeh, M. (2011). Feedback after good trials enhances intrinsic motivation. Research Quarterly for Exercise and Sport, 82, 360-364.

Badami, R., VaezMousavi, M., Wulf, G., \& Namazizadeh, M. (2012). Feedback about more accurate versus less accurate trials: Differential effects on self-confidence and activation. Research Quarterly for Exercise and Sport, 83, 196-203.

Bandura, A. (1977). Self-efficacy: Toward a unifying theory of behavioral change. Psychological Review, 84, 191-215.

Bandura, A. (1993). Perceived self-efficacy in cognitive development and functioning. Educational Psychologist, 28(2), 117-148.

Bandura, A. (1997). Self-efficacy: The exercise of control. New York: Freeman.

Bandura, A., \& Jourden, F. I. (1991). Self-regulatory mechanisms governing the impact of social comparison on complex decision making. Journal of Personality and Social Psychology, 60, 941-951.

Barker, J. B., Jones, M. V., \& Greenlees, I. (2010). Assessing the immediate and maintained effects of hypnosis on self-efficacy and soccer wall-volley performance. Journal of Sport \& Exercise Psychology, 32, 243-252.

Baumeister, R. F., \& Leary, M. R. (1995). The need to belong: Desire for interpersonal attachments as a fundamental human motivation. Psychological Bulletin, 117, 497-529.

Beilock, S. (2011). Choke: What the secrets of the brain reveal about getting it right when you have to. New York: Simon \& Schuster.

Bell, J. J., \& Hardy, J. (2009). Effects of attentional focus on skilled performance in golf. Journal of Applied Sport Psychology, 21, 163-177.

Berridge, K. C. (2007). The debate over dopamine's role in reward: The case for incentive salience. Psychopharmacology, 191, 391-431.

Biswal, B., Yetkin, F. Z., Haughton, V. M., \& Hyde, J. S. (1995). Functional connectivity in the motor cortex of resting human brain using echoplanar MRI. Magnetic Resonance in Medicine, 34, 537-541.

Blackwell, L. S., Trzesniewski, K. H., \& Dweck, C. S. (2007). Implicit theories of intelligence predict achievement across an adolescent transition: A longitudinal study and an intervention. Child Development, 78, 246-263.

Boekaerts, M. (1996). Self-regulated learning at the junction of cognition and motivation. European Psychologist, 1, 100-112.

Bollinger, J., Rubens, M. T., Zanto, T. P., \& Gazzaley, A. (2010). Expectation-driven changes in cortical functional connectivity influence working memory and long-term memory performance. Journal of Neuroscience, 30, 14399-14410.

Boureau, Y.-L., \& Dayan, P. (2011). Opponency revisited: Competition and cooperation between dopamine and serotonin. Neuropsychopharmacology Reviews, 36, 74-97.

Braver, T. S., Krug, M. K., Chiew, K. S., Kool, W., Westbrook, J. A., Clement, N. J., Somerville, L. H. (2014). Mechanisms of motivation-cognition interaction: Challenges and opportunities. Cognitive, Affective, \& Behavioral Neuroscience, 14, 443-472.

Brewer, J. A., Worhunskya, P. D., Gray, J. R., Tang, Y.-Y., Weber, J., \& Kober, H. (2011). Meditation experience is associated with differences in default mode network activity and connectivity. Proceedings of the National Academy of Sciences of the United States of America, 108, 20254-20259.

Broadbent, D. (1958). Perception and communication. London: Pergamon Press.
Brown, K. W., \& Ryan, R. M. (2003). The benefits of being present: Mindfulness and its role in psychological well-being. Journal of Personality and Social Psychology, 84, 822-848.

Buckner, R. L., Andrews-Hanna, J. R., \& Schacter, D. L. (2008). The brain's default network: Anatomy, function, and relevance to disease. Annals of the New York Academy of Sciences, 1124, 1-38. doi: 10.1196/annals.1440.011

Buckner, R. L. (2012). The serendipitous discovery of the brain's default network. NeuroImage, 62, 1137-1145.

Calin-Jageman, R. J., \& Caldwell, T. L. (2014). Replication of the superstition and performance study by Damisch, Stoberock, and Mussweiler (2010). Social Psychology, 45, 239-245.

Catania, A. C. (1975). Freedom and knowledge: An experimental analysis of preference in pigeons. Journal of Experimental Analysis of Behavior, 24, 89-106.

Catania, A. C., \& Sagvolden, T. (1980). Preference for free choice over forced choice in pigeons. Journal of Experimental Analysis of Behavior, 34, 77-86.

Chambon, V., \& Haggard, P. (2012). Sense of control depends on fluency of action selection, not motor performance. Cognition, 125, 441-451.

Chang, Y. K., Ho, L. A., Lu, F. J. H., Ou, C. C., Song, T. F. \& Gill, D. L. (2014). Self-talk and softball performance: The role of self-talk nature, motor task characteristics, and self-efficacy in novice softball players. Psychology of Sport and Exercise. 15, 139-145.

Chartrand, T. L., \& Bargh, J. A. (2002). Nonconscious motivations: Their activation, operation, and consequences. In A. Tesser, D. A. Stapel, \& J. V. Wood (Eds.), Self and motivation: Emerging psychological perspectives (pp. 13-41). Washington, DC: American Psychological Association.

Chauvel, G., Wulf, G., \& Maquestiaux, F. (2015). Visual illusions can facilitate sport skill learning. Psychonomic Bulletin \& Review, 22, 717-721.

Chen, D. D., Hendrick, J. L., \& Lidor, R. (2002). Enhancing selfcontrolled learning environments: The use of self-regulated feedback information. Journal of Human Movement Studies, 43, 69-86.

Chen, D., \& Singer, R. N. (1992). Self-regulation and cognitive strategies in sport participation. International Journal of Sport Psychology, 23, 277-300.

Chiviacowsky, S., \& Drews, R. (2014). Effects of generic versus nongeneric feedback on motor learning in children. PlosOne, 9, doi: 10. 1371/journal.pone.0088989

Chiviacowsky, S., \& Wulf, G. (2002). Self-controlled feedback: Does it enhance learning because performers get feedback when they need it? Research Quarterly for Exercise and Sport, 73, 408-415.

Chiviacowsky, S., \& Wulf, G. (2005). Self-controlled feedback is effective if it is based on the learner's performance. Research Quarterly for Exercise and Sport, 76, 42-48.

Chiviacowsky, S., \& Wulf, G. (2007). Feedback after good trials enhances learning. Research Quarterly for Exercise and Sport, 78, 40-47.

Chiviacowsky, S., Wulf, G., Laroque de Medeiros, F., Kaefer, A., \& Tani, G. (2008). Learning benefits of self-controlled knowledge of results in 10-year old children. Research Quarterly for Exercise and Sport, $79,405-410$

Chiviacowsky, S., Wulf, G., Lewthwaite, R., \& Campos, T. (2012a). Motor learning benefits of self-controlled practice in persons with Parkinson's disease. Gait \& Posture, 35, 601-605.

Chiviacowsky, S., Wulf, G., \& Lewthwaite, R. (2012b). Self-controlled learning: The importance of protecting perceptions of competence. Frontiers in Psychology, 3, 458. doi:10.3389/fpsyg.2012.00458

Chiviacowsky, S., Wulf, G., \& Ávila, L. (2013). An external focus of attention enhances motor learning in children with intellectual disabilities. Journal of Intellectual Disability Research, 57, 627-634.

Chiviacowsky, S., Wulf, G., \& Wally, R. (2010). An external focus of attention enhances balance learning in older adults. Gait \& Posture, $32,572-575$. 
Chiviacowsky, S., Wulf, G., Wally, R., \& Borges, T. (2009). KR after good trials enhances learning in older adults. Research Quarterly for Exercise and Sport, 80, 663-668.

Christina, R. W., \& Alpenfels, E. (2014). Influence of attentional focus on learning a swing path change. International Journal of Golf Science, 3, 35-49.

Cimpian, A., Arce, H.-M., Markman, E. M., \& Dweck, C. S. (2007). Subtle linguistic cues affect children's motivation. Psychological Science, 18, 314-316.

Clark, S. E., \& Ste-Marie, D. M. (2007). The impact of self-as-a-model interventions on children's self-regulation of learning and swimming performance. Journal of Sports Sciences, 25, 577-586.

Corbetta, M. (2012). Functional connectivity and neurological recovery. Developmental Psychobiology, 54, 239-253.

Costa, V. D., Tran, V., Turchi, J., \& Averbeck, B. B. (2014). Dopamine modulates novelty seeking behavior during decision making. Behavioral Neuroscience, 128, 556-566. doi:10.1037/a0037128

Craik, F. I. M., Moroz, T. M., Moscovitch, M., Stuss, D. T., Winocur, G., Tulving, E., \& Kapur, S. (1999). In search of the self: A positron emission tomography study. Psychological Science, 10, 27-35.

Csikszentmihalyi, M. (1990). Flow: The psychology of optimal experience. New York: Harper \& Row.

Damisch, L., Stoberock, B., \& Mussweiler, T. (2010). Keep your fingers crossed! How superstition improves performance. Psychological Science, 21, 1014-1020.

Dayan, E., \& Cohen, L. G. (2011). Neuroplasticity subserving motor skill learning. Neuron, 72, 443-454.

de la Fuente-Fernandez, R. (2009). The placebo-reward hypothesis: Dopamine and the placebo effect. Parkinsonism and Related Disorders, 15S3, S72-S74.

Deci, E. L., \& Ryan, R. M. (1985). Intrinsic motivation and selfdetermination in human behavior. New York: Plenum.

Deci, E. L., \& Ryan, R. M. (2000). The "what" and "why" of goal pursuits: Human needs and the self-determination of behavior. Psychological Inquiry, 11, 227-268.

Deci, E. L., \& Ryan, R. M. (2008). Self-Determination Theory: A macrotheory of human motivation, development, and health. Canadian Psychology, 49, 182-185.

Deci, E. L., Ryan, R. M., \& Koestner, R. (1999). A meta-analytic review of experiments examining the effects of extrinsic rewards on intrinsic motivation. Psychological Bulletin, 125, 627-668.

Delaveau, P., Salgado-Pineda, P., Fossati, P., Witjas, T., Azulay, J.-P., \& Blin, O. (2010). Dopaminergic modulation of the default mode network in Parkinson's disease. European Neuropsychopharmacology, 20, 784-792.

Demanet, J., Muhle-Karbe, P. S., Lynn, M. T., Blotenberg, I., \& Brass, M. (2013). Power to the will: How exerting physical effort boosts the sense of agency. Cognition, 129, 574-578.

Dewey, J. A., Seiffert, A. E., \& Carr, T. H. (2010). Taking credit for success: The phenomenology of control in a goal-directed task. Consciousness and Cognition, 19, 48-62.

Di, X., \& Biswal, B. B. (2015). Dynamic brain functional connectivity modulated by resting-state networks. Brain Structure and Function, $220,37-46$

Di, X., Zhu, S., Jin, H., Wang, P., Ye, Z., Zhou, K., Rao, H. (2012). Altered resting brain function and structure in professional badminton players. Brain Connectivity, 2, 225-233.

Dickerson, S. S., \& Kemeny, M. E. (2004). Acute stressors and cortisol responses: A theoretical integration and synthesis of laboratory research. Psychological Bulletin, 130, 355-391.

Doll, A., Hölzel, B. K., Boucard, C. C., Wohlschläger, A. M., \& Sorg, C. (2015). Mindfulness is associated with intrinsic functional connectivity between default mode and salience networks. Frontiers in Human Neuroscience, 9, 461. doi:10.3389/fnhum.2015.00461

Draganski, B., Kherif, F., Kloppel, S., Cook, P. A., Alexander, D. C., Parker, G. J. M., Frackowiak, R. S. J. (2008). Evidence for segregated and integrative connectivity patterns in the human basal ganglia. Journal of Neuroscience, 28, 7143-7152.

Draganski, B., \& May, A. (2008). Training-induced structural changes in the adult human brain. Behavioural Brain Research, 192, 137-142.

Dreisbach, G., \& Goschke, T. (2004). How positive affect modulates cognitive control: Reduced perseveration at the cost of increased distractibility. Journal of Experimental Psychology: Learning, Memory, and Cognition, 30, 343-353.

Drews, R., Chiviacowsky, S., \& Wulf, G. (2013). Children's motor skill learning is influenced by their conceptions of ability. Journal of Motor Learning and Development, 2, 38-44.

Ducharme, S. W., \& Wu, W. F. W. (2015). An external focus of attention improves stability after a perturbation during a dynamic balance task. Journal of Motor Learning and Development, 3, 74-90.

Durham, K., Van Vliet, P. M., Badger, F., \& Sackley, C. (2009). Use of information feedback and attentional focus of feedback in treating the person with a hemiplegic arm. Physiotherapy Research International, 14, 77-90.

Duzel, E., Bunzeck, N., Guitart-Masip, M., \& Duzel, S. (2010). NOveltyrelated Motivation of Anticipation and exploration by Dopamine (NOMAD): Implications for healthy aging. Neuroscience and Biobehavioral Reviews, 34, 660-669.

Dweck, C. S. (1999). Self-theories: Their role in motivation, personality, and development. Philadelphia: The Psychology Press.

Dweck, C. S., \& Leggett, E. L. (1988). A social-cognitive approach to motivation and personality. Psychological Review, 95, 256-273.

Eisenberger, N. I., Lieberman, M. D., \& Satpute, A. B. (2005). Personality from a control processing perspective: An fMRI study of neuroticism, extraversion, and self-consciousness. Cognitive, Affective, and Behavioral Neuroscience, 5, 169-181.

Eisenberger, R., Pierce, W. D., \& Cameron, J. (1999). Effects of reward on intrinsic motivation - negative, neutral, and positive: Comment on Deci, Koestner, and Ryan (1999). Psychological Bulletin, 125, 677-691.

Eitam, B., Kennedy, P. M., \& Higgins, E. T. (2013). Motivation from control. Experimental Brain Research, 229, 475-484.

Ennigkeit, F., \& Hänsel, F. (2014). Effects of exercise self-schema on reactions to self-relevant feedback. Psychology of Sport and Exercise, 15, 108-115.

Ewell, L. A., \& Leutgeb, S. (2014). Replay to remember: A boost from dopamine. Nature Neuroscience, 17, 1629-1631.

Feather, N. T. (1982). Expectancy-value approaches: Present status and future directions. In N. T. Feather (Ed.), Expectations and actions: Expectancy-value models in psychology (pp. 395-420). Hillsdale: Erlbaum

Feltz, D. L., Chow, D. M., \& Hepler, T. J. (2008a). Path analysis of selfefficacy and diving performance revisited. Journal of Sport and Exercise Psychology, 30, 401-411.

Feltz, D. L., Short, S. E., \& Sullivan, P. J. (2008b). Self-efficacy in sport. Champaign. IL: Human Kinetics.

Feltz, D. L., \& Wood, J. M. (2009). Can self-doubt be beneficial to performance? Exploring the concept of preparatory efficacy. The Open Sports Sciences Journal, 2, 65-70.

Fenton, S. A. M., Duda, J. L., Quested, E., \& Barrett, T. (2014). Coach autonomy support predicts autonomous motivation and daily moderate-to-vigorous physical activity and sedentary time in youth sport participants. Psychology of Sport and Exercise, 15, 453-463.

Ferguson, M. J., \& Bargh, J. A. (2004). How social perception can automatically influence behavior. Trends in Cognitive Sciences, 8, 33-39.

Finn, B., \& Miele, D. B. (2015). Hitting a high note on math tests: Remembered success influences test preferences. Journal of Experimental Psychology: Learning, Memory, and Cognition, Advance online publication. doi:10.1037/xlm0000150

Fiorillo, C. D., Newsome, W. T., \& Schultz, W. (2008). The temporal precision of reward prediction in dopamine neurons. Nature Neuroscience, 11, 966-973. 
Fiorio, M., Andani, M. E., Marotta, A., Classen, J., \& Tinazzi, M. (2014). Placebo-induced changes in excitatory and inhibitory corticospinal circuits during motor performance. Journal of Neuroscience, 34 , 3993-4005.

Floresco, S. B. (2015). The nucleus accumbens: An interface between cognition, emotion, and action. Annual Review Psychology, 66, 25-52.

Ford, P., Hodges, N. J., Huys, R., \& Williams, A. M. (2009). Evidence for end-point trajectory planning during a kicking action. Motor Control, 13, 1-24.

Fox, M. D., Snyder, A. Z., Vincent, J. L., Corbetta, M., Van Essen, D. C., \& Raichle, M. E. (2005). The human brain is intrinsically organized into dynamic, anticorrelated functional networks. Proceedings of the National Academy of Sciences of the United States of America, 102, 9673-9678.

Freedman, S. E., Maas, E., Caligiuri, M. P., Wulf, G., \& Robin, D. A. (2007). Internal vs. external: Oral-motor performance as a function of attentional focus. Journal of Speech, Language, and Hearing Science, 50, 131-136.

Freudenheim, A. M., Wulf, G., Madureira, F., \& Corrêa, S. C. P. (2010). An external focus of attention results in greater swimming speed. International Journal of Sports Science \& Coaching, 5, 533-542.

Friston, K. J. (2011). Functional and effective connectivity: A review. Brain Connectivity, 1, 13-36.

Frith, C. D. (2014). Action, agency and responsibility. Neuropsychologia, $55,137-142$

Gallagher, I. I. (2000). Philosophical conceptions of the self: Implications for cognitive science. Trends in Cognitive Sciences, 4, 14-21.

Gentsch, A., \& Synofzik, M. (2014). Affective coding: The emotional dimension of agency. Frontiers in Human Neuroscience, 8, 608. doi: 10.3389/fnhum.2014.00608

Green, T. D., \& Flowers, J. H. (1991). Implicit versus explicit learning processes in a probabilistic, continuous fine-motor catching task. Journal of Motor Behavior, 23, 293-300.

Greicius, M. D., Flores, B. H., Menon, V., Glover, G. H., Solvason, H. B., Kenna, H., Schatzberg, A. F. (2007). Resting-state functional connectivity in major depression: Abnormally increased contributions from subgenual cingulate cortex and thalamus. Biological Psychiatry, 62, 429-437.

Guadagnoli, M. A., \& Lee, T. D. (2004). Challenge point: A framework for conceptualizing the effects of various practice conditions in motor learning. Journal of Motor Behavior, 36, 212-224.

Guss-West, C., \& Wulf, G. (2016). Attentional focus in classical ballet: A survey of professional dancers. Journal of Dance Medicine \& Science (in press).

Gusnard, D. A., Akbudak, E., Shulman, G. L., \& Raichle, M. E. (2001). Medial prefrontal cortex and self-referential mental activity: Relation to a default mode of brain function. Proceedings of the National Academy of Sciences, 98, 4259-4264.

Guthrie, E. R. (1952). The psychology of learning. New York: Harper \& Row.

Hafenbrack, A. C., Kinias, Z., \& Barsade, S. G. (2013). Debiasing the mind through meditation: Mindfulness and the sunk-cost bias. Psychological Science, 25, 369-376.

Haggard, P., Clark, S., \& Kalogeras, J. (2002). Voluntary action and conscious awareness. Nature Neuroscience, 5, 382-385.

Hagger, M. S., Sultan, S., Hardcastle, S. J., \& Chatzisarantis, N. L. D. (2015). Perceived autonomy support and autonomous motivation toward mathematics activities in educational and out-of-school contexts is related to mathematics homework behavior and attainment. Contemporary Educational Psychology, 41, 111-123.

Halperin, I., Chapman, D. T., Martin, D. T., Abbiss, C., \& Wulf, G. (2015). Coaching cues in amateur boxing: An analysis of feedback provided between rounds of competition. Manuscript submitted for publication.

Halperin, I., Chapman, D. T., Martin, D. T., \& Wulf, G. (2015). Choices enhance punching performance: An exploratory case study of a world champion kickboxer. Manuscript submitted for publication.
Hardy, J., Begley, K., \& Blanchfield, A. W. (2015). It's good but it's not right: Instructional self-talk and skilled performance. Journal of Applied Sport Psychology, 27, 132-139.

Hartman, J. M. (2007). Self-controlled use of a perceived physical assistance device during a balancing task. Perceptual and Motor Skills, 104, 1005-1016.

Hasan, A., Galea, J. M., Casula, E. P., Falkai, P., Bestmann, S., \& Rothwell, J. C. (2013). Muscle and timing-specific functional connectivity between the dorsolateral prefrontal cortex and the primary motor cortex. Journal of Cognitive Neuroscience, 25, 558-570.

Herbert, C., Pauli, P., \& Herbert, B. M. (2011). Self-reference modulates the processing of emotional stimuli in the absence of explicit selfreferential appraisal instructions. Social Cognitive and Affective Neuroscience, 6, 653-661.

Hooyman, A., Wulf, \& Lewthwaite, R. (2014). Impacts of autonomysupportive versus controlling instructional language on motor learning. Human Movement Science, 36, 190-198.

Hosp, J. A., Pekanovic, A., Rioult-Pedotti, M. S., \& Luft, A. R. (2011). Dopaminergic projections from midbrain to primary motor cortex mediate motor skill learning. Journal of Neuroscience, 31, 2481-2487.

Huet, M., Camachon, C., Fernandez, L., Jacobs, D. M., \& Montagne, G. (2009a). Self-controlled concurrent feedback and the education of attention towards perceptual invariants. Human Movement Science, $28,450-467$.

Huet, M., Jacobs, D. M., Camachon, C., Goulon, C., \& Montagne, G. (2009b). Self-controlled concurrent feedback facilitates the learning of the final approach phase in a fixed-base flight simulator. Human Factors, 51, 858-871.

Hughes, M. L., Geraci, L., \& De Forrest, R. L. (2013). Aging 5 years in 5 minutes: The effect of taking a memory test on older adults' subjective age. Psychological Science, 24, 2481-2488.

Hutchinson, J. C., Sherman, T., Martinovic, N., \& Tenenbaum, G. (2008). The effect of manipulated self-efficacy on perceived and sustained effort. Journal of Applied Sport Psychology, 20, 457-472.

Ille, A., Selin, I., Do, M.-C., \& Thon, B. (2013). Attentional focus effects on sprint start performance as a function of skill level. Journal of Sports Sciences, 31, 1705-1712.

Ito, T., Matsuda, T., \& Shimojo, S. (2015). Functional connectivity of the striatum in experts of stenography. Brain and Behavior, 5. doi: 10. $1002 /$ brb3.333

Jackson, B. H., \& Holmes, A. M. (2011). The effects of focus of attention and task objective consistency on learning a balance task. Research Quarterly for Exercise and Sport, 82, 574-579.

Jalene, S., \& Wulf, G. (2014). Brief hypnotic intervention increases throwing accuracy. International Journal of Sports Science \& Coaching, 9, 199-206.

James, W. (1890). The principles of psychology (Vol. 2). New York: Holt.

Janelle, C. M., Barba, D. A., Frehlich, S. G., Tennant, L. K., \& Cauraugh, J. H. (1997). Maximizing performance effectiveness through videotape replay and a self-controlled learning environment. Research Quarterly for Exercise and Sport, 68, 269-279.

Jiao, J., Du, F., He, X., \& Zhang, K. (2015). Social comparison modulates reward-driven attentional capture. Psychonomic Bulletin \& Review, 22, 1278-1284.

Johnson, L., Burridge, J. H., \& Demain, S. H. (2013). Internal and external focus of attention during gait re-education: An observational study of physical therapist practice in stroke rehabilitation. Physical Therapy, 93, 957-966.

Johnson, M. K., Raye, C. L., Mitchell, K. J., Touryan, S. R., Greene, E. J., \& Nolen-Hoeksema, S. (2006). Dissociating medial frontal and posterior cingulate activity during self-reflection. Social Cognitive and Affective Neuroscience, 1, 56-64.

Jourden, F. J., Bandura, A., \& Banfield, J. T. (1991). The impact of conceptions of ability on self-regulatory factors and motor skill acquisition. Journal of Sport \& Exercise Psychology, 8, 213-226. 
Kal, E. C., van der Kamp, J., \& Houdijk, H. (2013). External attentional focus enhances movement automatization: A comprehensive test of the constrained action hypothesis. Human Movement Science, 32, 527-539.

Karsh, N., \& Eitam, B. (2015). I control therefore I do: Judgments of agency influence action selection. Cognition, 138, 122-131.

Kee, Y. H., Chatzisarantis, N. L., Kong, P. W., Chow, J. Y., \& Chen, L. H. (2012). Mindfulness, movement control and attentional focus strategies: Effects of mindfulness on a postural balance task. Journal of Sport and Exercise Psychology, 34, 561-579.

Kim, W., Chang, Y., Kim, J., Seo, J., Ryu, K., Lee, E., Woo, M., \& Janelle, C. M. (2014). An fMRI study of differences in brain activity among elite, expert, and novice archers at the moment of optimal aiming. Cognitive \& Behavioral Neurology, 27, 173-182.

Kim, J. H., Han, J. K., Kim, B.-N., \& Han, D. H. (2015). Brain networks governing the golf swing in professional golfers. Journal of Sports Sciences, 33, 1980-1987.

Kim, K., \& Johnson, M. K. (2012). Extended self: Medial prefrontal activity during transient association of self and objects. Social Cognitive and Affective Neuroscience, 7, 199-207.

Kirschenbaum, D. S. (1984). Self-regulation and sport psychology: Nurturing an emerging symbiosis. Journal of Sport Psychology, 6, 159-183.

Klein, P.-A., Petitjean, C., Olivier, E., \& Duque, J. (2014). Top-down suppression of incompatible motor activations during response selection under conflict. NeuroImage, 86, 138-149.

Koepp, M. J., Gunn, R. N., Lawrence, A. D., Cunningham, V. J., Dagher, A., Jones, T., Grasby, P. M. (1998). Evidence for striatal dopamine release during a video game. Nature, 393, 266-268.

Kojovic, M., Mir, P., Trender-Gerhard, I., Schneider, S. A., Pareés, I., Edwards, M. J., Jahanshahi, M. (2014). Motivational modulation of bradykinesia in Parkinson's disease off and on dopaminergic medication. Journal of Neurology, 261, 1080-1089. doi: 10.1007/ s00415-014-7315-x

Kühn, A. A., Brücke, C., Hübl, J., Schneider, G.-H., Kupsch, A., Eusebio, A., Ashkan, K., Holland, P., Aziz, T., Vandenberghe, W., Nuttin, B., \& Brown, P. (2008). Motivation modulates motorrelated feedback activity in the human basal ganglia. Current Biology, 18, R648-R650.

Lamarche, L., Gammage, K. L., \& Adkin, A. L. (2011). Can balance efficacy be manipulated using verbal feedback? Canadian Journal of Experimental Psychology, 65, 277-284.

Lancaster, T. M., Heerey, E. A., Mantripragada, K., \& Linden, D. E. J. (2015). Replication study implicates COMT val158met polymorphism as a modulator of probabilistic reward learning. Genes, Brain and Behavior, 14, 486-492.

Landers, M., Wulf, G., Wallmann, H., \& Guadagnoli, M. A. (2005). An external focus of attention attenuates balance impairment in Parkinson's disease. Physiotherapy, 91, 152-185.

Laufer, Y., Rotem-Lehrer, N., Ronen, Z., Khayutin, G., \& Rozenberg, I. (2007). Effect of attention focus on acquisition and retention of postural control following ankle sprain. Archives of Physical Medicine and Rehabilitation, 88, 105-108.

Lee, C., Linkenauger, S. A., Bakdash, J. Z., Joy-Gaba, J. A., \& Proffitt, D. R. (2011). Putting like a pro: The role of positive contagion in golf performance and perception. PLOS ONE, 6. doi: 10.1371/journal. pone. 0026016

Lee, T. D., Swinnen, S. P., \& Serrien, D. J. (1994). Cognitive effort and motor learning. Quest, 46, 328-344.

Legault, L., \& Inzlicht, M. (2013). Self-determination, self-regulation, and the brain: Autonomy improves performance by enhancing neuroaffective responsiveness to self-regulation failure. Journal of Personality and Social Psychology, 105, 123-138.

Leotti, L. A., \& Delgado, M. R. (2011). The inherent reward of choice. Psychological Science, 22, 1310-1318.

Leotti, L. A., Iyengar, S. S., \& Ochsner, K. N. (2010). Born to choose: The origins and value of the need for control. Trends in Cognitive Science, 14, 457-463.
Lewthwaite, R., Chiviacowsky, S., Drews, R., \& Wulf, G. (2015). Choose to move: The motivational impact of autonomy support on motor learning. Psychonomic Bulletin \& Review, 22, 1383-1388.

Lewthwaite, R., \& Wulf, G. (2010a). Grand challenge for movement science and sport psychology: Embracing the social-cognitiveaffective-motor nature of motor behavior. Frontiers in Psychology, 1(Article 42), 1-3. doi:10.3389/fpsyg.2010.00042

Lewthwaite, R., \& Wulf, G. (2010b). Social-comparative feedback affects motor skill learning. Quarterly Journal of Experimental Psychology, 63, 738-749.

Lewthwaite, R., \& Wulf, G. (2012). Motor learning through a motivational lens. In N. J. Hodges \& A. M. Williams (Eds.), Skill acquisition in sport: Research, theory \& practice (2nd ed., pp. 173-191). London: Routledge.

Li, G., He, H., Huang, M., Zhang, X., Lu, J., Lai, Y., Yao, D. (2015). Identifying enhanced cortico-basal ganglia loops associated with prolonged dance training. Scientific Reports, 5, 10271. doi: 10. 1038/srep10271

Liao, C. M., \& Masters, R. S. W. (2001). Analogy learning: A means to implicit motor learning. Journal of Sports Sciences, 19, 307-319.

Lidstone, S. C., Schulzer, M., Dinelle, K., Mak, E., Sossi V., Ruth, T. J., Stoessl A. J. (2010). Effects of expectation on placebo-induced dopamine release in Parkinson disease. Archives of General Psychiatry, 67, 857-865.

Lighthall, N. R., Marissa, A., Gorlick, M. A., Schoeke, A., Frank, M. J., $\&$ Mather, M. (2013). Stress modulates reinforcement learning in younger and older adults. Psychology and Aging, 28, 35-46.

Linkenauger, S. A., Witt, J. K., Stefanucci, J. K., Bakdash, J. Z., \& Proffitt, D. R. (2009). The effects of handedness and reachability on perceived distance. Journal of Experimental Psychology. Human Perception and Performance, 35, 1649-1660.

Locke, E. A., \& Latham, G. P. (2006). New directions in goal-setting theory. Current Directions In Psychological Science, 15, 265-268.

Lohse, K. R. (2012). The influence of attention on learning and performance: Pre-movement time and accuracy in an isometric force production task. Human Movement Science, 31, 12-25.

Lohse, K. R., Jones, M. C., Healy, A. F., \& Sherwood, D. E. (2014). The role of attention in motor control. Journal of Experimental Psychology: General, 143, 930-948.

Lohse, K. R., \& Sherwood, D. E. (2012). Thinking about muscles: The neuromuscular effects of attentional focus on accuracy and fatigue. Acta Psychologica, 140, 236-245.

Lohse, K. R., Sherwood, D. E., \& Healy, A. F. (2010). How changing the focus of attention affects performance, kinematics, and electromyography in dart throwing. Human Movement Science, 29, 542-555.

Lohse, K. R., Sherwood, D. E., \& Healy, A. F. (2011). Neuromuscular effects of shifting the focus of attention in a simple force production task. Journal of Motor Behavior, 43, 173-184.

Lohse, K. R., Wulf, G., \& Lewthwaite, R. (2012). In N. J. Hodges \& A. M. Williams (Eds.), Skill acquisition in sport: Research, theory \& practice (2nd ed., pp. 40-58). London: Routledge.

Loosch, E. (1995). Funktionelle Variabilität in Dartwurf (Functional variability in dart throwing). Sportwissenschaft, 25, 417-425.

Lutz, K., Pedroni, A., Nadig, K., Luechinger, R., \& Jäncke, L. (2012). The rewarding value of good motor performance in the context of monetary incentives. Neuropsychologia, 50, 1739-1747.

Lyubomirsky, S., King, L., \& Diener, E. (2005). The benefits of frequent positive affect: Does happiness lead to success? Psychological Bulletin \& Review, 131, 803-855.

Mangels, J. A., Butterfield, B., Lamb, J., Good, C., \& Dweck, C. S. (2006). Why do beliefs about intelligence influence learning success? A social cognitive neuroscience model. Social Cognitive and Affective Neuroscience, 1, 75-86.

Marchant, D. C. (2011). Attentional focusing instructions and force production. Frontiers in Psychology, 1, 210. doi:10.3389/fpsyg.2010.00210 
Marchant, D. C., Clough, P. J., Crawshaw, M., \& Levy, A. (2009a). Novice motor skill performance and task experience is influenced by attentional focus instructions and instruction preferences. International Journal of Sport and Exercise Psychology, 7, 488-502.

Marchant, D. C., Clough, P. J., \& Crawshaw, M. (2007). The effects of attentional focusing strategies on novice dart throwing performance and their task experiences. International Journal of Sport and Exercise Psychology, 5, 291-303.

Marchant, D. C., Greig, M., Bullough, J., \& Hitchen, D. (2011). Instructions to adopt an external focus enhance muscular endurance. Research Quarterly for Exercise and Sport, 82, 466-473.

Marchant, D. C., Greig, M., \& Scott, C. (2008). Attentional focusing strategies influence bicep EMG during isokinetic bicep curls. Athletic Insight, 10(2).

Marchant, D. C., Greig, M., \& Scott, C. (2009b). Attentional focusing instructions influence force production and muscular activity during isokinetic elbow flexions. Journal of Strength and Conditioning Research, 23, 2358-2366.

Marsden, K. E., Ma, W. J., Deci, E. L., Ryan, R. M., \& Chiu, P. H. (2015). Diminished neural responses predict enhanced intrinsic motivation and sensitivity to external incentive. Cognitive, Affective, and Behavioral Neuroscience, 15, 276-286.

Maslovat, D., Hayes, S. J., Horn, R., \& Hodges, N. J. (2010). Motor learning through observation. In D. Elliott \& M. A. Horn (Eds.), Vision and goal-directed movement: Neurobehavioral perspectives (pp. 315-340). Champaign: Human Kinetics.

Masters, R. S. W. (1992). Knowledge, knerves and know-how: The role of explicit versus implicit knowledge in the breakdown of a complex motor skill under pressure. British Journal of Psychology, 83, 343358.

Masters, R. S. W., \& Poolton, J. (2012). Advances in implicit motor learning. In N. J. Hodges \& A. M. Williams (Eds.), Skill acquisition in sport: Research, theory and practice (pp. 59-75). London: Routledge.

Maxwell, J. P., Masters, R. S. W., \& Eves, F. F. (2000). From novice to no know-how: A longitudinal study of implicit motor learning. Journal of Sports Science, 18, 111-120.

McCombs, M. L. (1989). Self-regulated learning and achievement: A phenomenological view. In B. J. Zimmerman \& D. H. Schunk (Eds.), Self-regulated learning and academic achievement theory, research, and practice: Progress in cognitive development research (pp. 51-82). New York: Springer.

McKay, B., Lewthwaite, R., \& Wulf, G. (2012). Enhanced expectancies improve performance under pressure. Frontiers in Psychology, 3, 8 . doi:10.3389/fpsyg.2012.00008

McKay, B., \& Wulf, G. (2012). A distal external focus enhances dart throwing performance. International Journal of Sport and Exercise Psychology, 10, 149-156.

McKay, B., Wulf, G., Lewthwaite, R., \& Nordin, A. (2015). The self: Your own worst enemy? A test of the self-invoking trigger hypothesis. Quarterly Journal of Experimental Psychology, 68, 1910-1919.

McKiernan, K. A., Kaufman, J. N., Kucera-Thompson, J., \& Binder, J. R. (2003). A parametric manipulation of factors affecting task-induced deactivation in functional neuroimaging. Journal of Cognitive Neuroscience, 15, 394-408.

McNevin, N. H., Shea, C. H., \& Wulf, G. (2003). Increasing the distance of an external focus of attention enhances learning. Psychological Research, 67, 22-29.

Menon, V. (2015). Salience network. In A. W. Toga (Ed.), Brain mapping: An encyclopedic reference (Vol. 2, pp. 597-611). London: Academic Press: Elsevier.

Milton, J., Solodkin, A., Hluštík, P., \& Small, S. L. (2007). The mind of expert motor performance is cool and focused. NeuroImage, 35, 804-813.

Montoya, E. R., Bos, P. A., Terburg, D., Rosenberger, L. A., \& van Honk, J. (2014). Cortisol administration induces global down-regulation of the brain's reward circuitry. Psychoneuroendocrinology, 47, 31-42.
Moore, L. J., Vine, S. J., Freeman, P., \& Wilson, M. R. (2013). Quiet eye training promotes challenge appraisals and aids performance under elevated anxiety. International Journal of Sport and Exercise Psychology, 11, 169-183.

Mooshagian, E., Keisler, A., Zimmermann, T., Schweickert, J. M., \& Wassermann, E. M. (2015). Modulation of corticospinal excitability by reward depends on task framing. Neuropsychologia, 68, 31-37.

Moritz, S. E., Feltz, D. L., Fahrbach, K., \& Mack, D. (2000). The relation of self-efficacy measures to sport performance: A meta-analytic review. Research Quarterly for Exercise and Sport, 71, 280-294.

Müller, H., \& Loosch, E. (1999). Functional variability and an equifinal path of movement during targeted throwing. Journal of Human Movement Studies, 36, 103-126.

Murayama, K., Matsumoto, M., Izuma, K., Sugiura, A., Ryan, R. M., Deci, E. L., \& Matsumoto, K. (2015). How self-determined choice facilitates performance: A key role of the ventromedial prefrontal cortex. Cerebral Cortex, 25, 1241-1251.

Murayama, K., Matsumoto, M., Izuma, K., \& Matsumoto, K. (2010). Neural basis of the undermining effect of monetary reward on intrinsic motivation. Proceedings of the National Academy of Sciences of the United States of America, 107, 20911-20916.

Murty, V. P., \& Adcock, R. A. (2014). Enriched encoding: Reward motivation organizes cortical networks for hippocampal detection of unexpected events. Cerebral Cortex, 24, 2160-2168.

Neiss, R. (1989). Expectancy in motor behavior: A crucial element of the psychobiological states that affect performance. Human Performance, 2, 273-300.

Neumann, D. L., \& Brown, J. (2013). The effect of attentional focus strategy on physiological and motor performance during a sit-up exercise. Journal of Psychophysiology, 27, 7-15.

Nieoullon, A., \& Coquerel, A. (2003). Dopamine: A key regulator to adapt action, emotion, motivation and cognition. Current Opinion in Neurology, 16(Suppl. 2), S3-S9.

Northoff, G., Heinzel, A., de Greck, M., Bermpohl, F., Dobrowolny, H., \& Panksepp, J. (2006). Self-referential processing in our brain - A metaanalysis of imaging studies on the self. Neuroimage, 31, 440-457.

O'Neill, G. C., Bauer, M., Woolrich, M. W., Morris, P. G., Barnes, G. R., \& Brookes, M. J. (2015). Dynamic recruitment of resting state subnetworks. NeuroImage, 115, 85-95.

Ong, N. T., Bowcock, A., \& Hodges, N. J. (2010). Manipulations to the timing and type of instructions to examine motor skill performance under pressure. Frontiers in Psychology, 1, 196. doi:10.3389/fpsyg. 2010.00196

Ong, N. T., \& Hodges, N. J. (2012). Mixing it up a little: How to schedule observational practice. In N. J. Hodges \& M. A. Williams (Eds.), Skill acquisition in sport: Research, theory \& practice (pp. 22-39). London: Routledge.

Palmer, K., Chiviacowsky, S., \& Wulf, G. (2016). Enhanced expectancies facilitate golf putting. Psychology of Sport and Exercise, 22, 229-232.

Parr, R., \& Button, C. (2009). End-point focus of attention: Learning the "catch" in rowing. International Journal of Sport Psychology, 40, 616-635.

Pascua, L. A. M., Wulf, G., \& Lewthwaite, R. (2015). Additive benefits of external focus and enhanced performance expectancy for motor learning. Journal of Sports Sciences, 33, 58-66.

Patall, E. A., Cooper, H., \& Robinson, J. C. (2008). The effects of choice on intrinsic motivation and related outcomes: A meta-analysis of research findings. Psychological Bulletin, 134, 270-300.

Patterson, J. T., \& Carter, M. (2010). Learner regulated knowledge of results during the acquisition of multiple timing goals. Human Movement Science, 29, 214-227.

Patterson, J. T., Carter, M., \& Sanli, E. (2011). Decreasing the proportion of self-control trials during the acquisition period does not compromise the learning advantages in a self-controlled context. Research Quarterly for Exercise and Sport, 82, 624-633. 
Patterson, J. T., \& Lee, T. D. (2010). Self-regulated frequency of augmented information in skill learning. Canadian Journal of Experimental Psychology, 63, 33-40.

Perreault, M. E., \& French, K. E. (2015). External-focus feedback benefits free-throw learning in children. Research Quarterly for Exercise and Sport, 86, 422-427.

Pessiglione, M., Schmidt, L., Draganski, B., Kalisch, R., Lau, H., Dolan, R. J., \& Frith, C. D. (2007). How the brain translates money into force. A neuro-imaging study of subliminal motivation. Science, 316, 904-906.

Piedimonte, A., Benedetti, F., \& Carlino, E. (2015). Placebo-induced decrease in fatigue: Evidence for a central action on the preparatory phase of movement. European Journal of Neuroscience, 41, 492-497.

Plaks, J. E., \& Stecher, K. (2007). Unexpected improvement, decline, and stasis: A prediction confidence perspective on achievement success and failure. Journal of Personality and Social Psychology, 93, 667-684.

Porter, J. M., Anton, P. M., \& Wu, W. F. W. (2012). Increasing the distance of an external focus of attention enhances standing long jump performance. Journal of Strength and Conditioning Research, 26, 2389-2393.

Porter, J. M., Nolan, R. P., Ostrowski, E. J., \& Wulf, G. (2010a). Directing attention externally enhances agility performance: A qualitative and quantitative analysis of the efficacy of using verbal instructions to focus attention. Frontiers in Psychology, 1, 216. doi:10.3389/fpsyg. 2010.00216

Porter, J. M., Ostrowski, E. J., Nolan, R. P., \& Wu, W. F. W. (2010b). Standing long-jump performance is enhanced when using an external focus of attention. Journal of Strength \& Conditioning Research, 24, 1746-1750.

Porter, J. M., Wu, W. F. W., \& Partridge, J. A. (2010c). Focus of attention and verbal instructions: Strategies of elite track and field coaches and athletes. Sport Science Review, 19, 199-211.

Post, P. G., Fairbrother, J. T., Barros, J. A., \& Kulpa, J. D. (2014). Selfcontrolled practice within a fixed time period facilitates the learning of a basketball set shot. Journal of Motor Learning and Development, 2, 9-15.

Post, P. G., Fairbrother, J. T., \& Barros, J. A. (2011). Self-controlled amount of practice benefits the learning of a motor skill. Research Quarterly for Exercise and Sport, 82, 474-481.

Radel, R., Sarrazin, P., \& Pelletier, L. (2009). Evidence of subliminally primed motivational orientations: The effects of unconscious motivational processes on the performance of a new motor task. Journal of Sport and Exercise Psychology, 31, 657-674.

Raichle, M. E. (2015). The brain's default mode network. Annual Review of Neuroscience, 38, 433-447.

Reeve, J., \& Tseng, C. M. (2011). Cortisol reactivity to a teacher's motivating style: The biology of being controlled versus supporting autonomy. Motivation and Emotion, 35, 63-74.

Ridderinkhof, K. R., van Wouwe N. C., Band, G. P., Wylie, S. A., Van der Stigchel, S., van Hees, P., van den Wildenberg, W. P. (2012). A tribute to Charlie Chaplin: Induced positive affect improves reward-based decision-learning in Parkinson's disease. Frontiers in Psychology, 3 (Article 185). doi: 10.3389/fpsyg.2012.00185

Rosenqvist, O., \& Skans, O. N. (2015). Confidence enhanced performance? - The causal effects of success on future performance in professional golf tournaments. Journal of Economic Behavior \& Organization, 117, 281-295.

Rotem-Lehrer, N., \& Laufer, Y. (2007). Effect of focus of attention on transfer of a postural control task following an ankle sprain. Journal of Orthopaedic and Sports Physical Therapy, 37, 564-569.

Rowe, J. B., Eckstein, D., Braver, T., \& Owen, A. M. (2008). How does reward expectation influence cognition in the human brain? Journal of Cognitive Neuroscience, 20, 1980-1992.

Rudman, L. A., Dohn, M. C., \& Fairchild, K. (2007). Implicit self-esteem compensation: Automatic threat defense. Journal of Personality and Social Psychology, 93, 798-813.
Russell, R., Porter, J., \& Campbell, O. (2014). An external skill focus is necessary to enhance performance. Journal of Motor Learning and Development, 2, 37-46.

Ryan, R. M., \& Deci, E. L. (2000). Self-Determination Theory and the facilitation of intrinsic motivation, social development, and wellbeing. American Psychologist, 55, 68-78.

Saemi, E., Porter, J. M., Ghotbi-Varzaneh, A., Zarghami, M., \& Maleki, F. (2012). Knowledge of results after relatively good trials enhances self-efficacy and motor learning. Psychology of Sport and Exercise, $13,378-382$

Saemi, E., Wulf, G., Varzaneh, A. G., \& Zarghami, M. (2011). Feedback after good versus poor trials enhances motor learning in children. Revista Brasileira de Educação Física e Esporte (Brazilian Journal of Physical Education and Sport), 25, 671-679.

Salmoni, A. W., Schmidt, R. A., \& Walter, C. B. (1984). Knowledge of results and motor learning: A review and critical appraisal. Psychological Bulletin, 95, 355-386.

Sanli, E. A., Patterson, J. T., Bray, S. R., \& Lee, T. D. (2013). Understanding self-controlled motor learning protocols through self-determination theory. Frontiers in Psychology, 3, 611. doi:10. 3389/fpsyg.2012.00611

Schmidt, R. A. (1975). A schema theory of discrete motor skill learning. Psychological Review, 82, 225-260.

Schmidt, R. A., \& Bjork, R. A. (1992). New conceptualizations of practice: Common principles in three paradigms suggest new principles for training. Psychological Science, 3, 207-217.

Schmidt, L., Braun, E. K., Wager, T. D., \& Shohamy, D. (2014). Mind matters: Placebo enhances reward learning in Parkinson's disease. Nature Neuroscience, 17, 1793-1797.

Schmidt, L., Lebreton, M., Clery-Melin, M-L., Daunizeau, J., \& Pessiglione, M. (2012). Neural mechanisms underlying motivation of mental versus physical effort. PLoS Biology, 10. doi: 10.1371/ journal.pbio.1001266

Schücker, L., Anheier, W., Hagemann, N., Strauss, B., \& Völker, K. (2013). On the optimal focus of attention for efficient running at high intensity. Sport, Exercise, and Performance Psychology, 2, 207-219.

Schücker, L., Hagemann, N., Strauss, B., \& Völker, K. (2009). The effect of attentional focus on running economy. Journal of Sports Sciences, 27, 1241-1248.

Schultz, W. (1998). Predictive reward signal of dopamine neurons. Journal of Neurophysiology, 80, 1-27.

Schultz, W. (2000). Multiple reward signals in the brain. Nature Reviews Neuroscience, 1, 199-207.

Schultz, W. (2010). Review of dopamine signals for reward value and risk: Basic and recent data. Behavioral and Brain Functions, 6, 24. doi:10.1186/1744-9081-6-24

Schultz, W. (2013). Updating dopamine reward signals. Current Opinion in Neurobiology, 23, 229-238.

Shafizadeh, M., Platt, G. K., \& Bahram, A. (2013). Effects of focus of attention and type of practice on learning and self-efficacy in dart throwing. Perceptual and Motor Skills, 117, 182-192.

Shea, C. H., \& Wulf, G. (1999). Enhancing motor learning through external-focus instructions and feedback. Human Movement Science, $18,553-571$

Shea, C. H., Wulf, G., Whitacre, C., \& Park, J. H. (2001). Surfing the implicit wave. Quarterly Journal of Experimental Psychology, 54A, 841-862.

Shmuelof, L., \& Krakauer, J. W. (2011). Are we ready for a natural history of motor learning? Neuron, 72, 469-476.

Shohamy, D., \& Adcock, R. A. (2010). Dopamine and adaptive memory. Trends in Cognitive Sciences, 14, 464-472.

Shomstein, S., \& Johnson, J. (2013). Shaping attention with reward: Effects of reward on space- and object-based selection. Psychological Science, 24, 2369-2378. 
Shors, T. J. (2014). The adult brain makes new neurons, and effortful learning keeps them alive. Current Directions in Psychological Science, 23, 311-318.

Song, S., Gotts, S. J., Dayan, E., \& Cohen, L. G. (2015). Practice structure improves unconscious transitional memories by increasing synchrony in a premotor network. Journal of Cognitive Neuroscience, 27, 1503-1512. doi:10.1162/jocn_a_00796

Southard, D. (2011). Attentional focus and control parameter: Effect on throwing pattern and performance. Research Quarterly for Exercise and Sport, 82, 652-666.

Sridharan, D., Levitin, D. J., \& Menon, V. (2008). A critical role for the right fronto-insular cortex in switching between central-executive and default-mode networks. Proceedings of the National Academy of Sciences of the United States of America, 105, 12569-12574.

Ste-Marie, D. M., Vertest, K., Rymal, A. M., \& Martini, R. (2011). Feedforward self-modeling enhances skill acquisition in children learning trampoline skills. Frontiers in Psychology, 2, 155. doi:10. 3389/fpsyg.2011.00155

Stephens, M. A. P., Franks, M. M., Rook, K. S., Iida, M., Hemphill, R. C., \& Salem, J. K. (2013). Spouses attempts to regulate day-to-day dietary adherence among patients with Type 2 diabetes. Health Psychology, 32, 1029-1037.

Sternberg, S. (1969). The discovery of processing stages: Extensions of Donders' method. In W. G. Koster (Ed.), Attention and performance II (pp. 276-315). Amsterdam: North-Holland.

Stevens, D., Anderson, D. I., O'Dwyer, N. J., \& Williams, A. M. (2012). Does self-efficacy mediate transfer effects in the learning of easy and difficult motor skills? Consciousness and Cognition, 21, 1122-1128.

Stoate, I., \& Wulf, G. (2011). Does the attentional focus adopted by swimmers affect their performance? International Journal of Sport Science \& Coaching, 6, 99-108.

Stoate, I., Wulf, G., \& Lewthwaite, R. (2012). Enhanced expectancies improve movement efficiency in runners. Journal of Sports Sciences, 30, 815-823.

Stone, J., Lynch, C. I., Sjomeling, M., \& Darley, J. M. (1999). Stereotype threat effects on black and white athletic performance. Journal of Personality and Social Psychology, 77, 1213-1227.

Sugawara, S. K., Tanaka, S., Okazaki, S., Watanabe, K., Sadato, N. (2012). Social rewards enhance offline improvements in motor skill. PLoS ONE, 7, doi: 10.1371/journal.pone.0048174

Sugiura, M., Watanabe, J., Maeda, Y., Matsue, Y., Fukuda, H., \& Kawashima, R. (2005). Cortical mechanisms of visual self-recognition. NeuroImage, 24, 143-149.

Taren, A. A., Gianaros, P. J., Greco, C. M., Lindsay, E. K., Fairgrieve, A., Brown, K. W., Creswell, J. D. (2015). Mindfulness meditation training alters stress-related amygdala resting state functional connectivity: A randomized controlled trial. Social Cognitive and Affective Neuroscience. doi:10.1093/scan/nsv066

Taylor, G., Jungert, T., Mageau, G. A., Schattke, K., Dedic, H., Rosenfield, S., \& Koestner, R. (2014). A self-determination theory approach to predicting school achievement over time: The unique role of intrinsic motivation. Contemporary Educational Psychology, 39, 342-358.

Themanson, J. R., Hillman, C. H., McAuley, E., Buck, S. M., Doerksen, S. E., Morris, K. S., \& Pontifex, M. B. (2008). Self-efficacy effects on neuroelectric and behavioral indices of action monitoring in older adults. Neurobiology of Aging, 29, 1111-1122.

Themanson, J. R., Pontifex, M. B., Hillman, C. H., \& McAuley, E. (2011). The relation of self-efficacy and error-related self-regulation. International Journal of Psychophysiology, 80, 1-10.

Themanson, J. R., \& Rosen, P. J. (2015). Examining the relationships between self-efficacy, task-relevant attentional control, and task performance: Evidence from event-related brain potentials. British Journal of Psychology, 106, 253-271.

Theodorakis, Y. (1995). Effects of self-efficacy, satisfaction, and personal goals on swimming performance. Sport Psychologist, 9, 245-253.
Tiger, J. H., Hanley, G. P., \& Hernandez, E. (2006). An evaluation of the value of choice with preschool children. Journal of Applied Behavior Analysis, 39, 1-16.

Totsika, V., \& Wulf, G. (2003). The influence of external and internal foci of attention on transfer to novel situations and skills. Research Quarterly for Exercise and Sport, 74, 220-225.

Trempe, M., Sabourin, M., \& Proteau, L. (2012). Success modulates consolidation of a visuomotor adaptation task. Journal of Experimental Psychology: Learning, Memory, and Cognition, 38, 52-60.

Tzetzis, G., Votsis, E., \& Kourtessis, T. (2008). The effect of different corrective feedback methods on the outcome and self confidence of young athletes. Journal of Sports Science and Medicine, 7, 371-378.

van Eimeren, T., Monchi, O., Ballanger, B., \& Strafella, A. P. (2009). Dysfunction of the default mode network in Parkinson disease. Archives of Neurology, 66, 877-883.

van Elswijk, G., Kleine, B. U., Overeem, S., \& Stegeman, D. F. (2007). Expectancy induces dynamic modulation of corticospinal excitability. Journal of Cognitive Neuroscience, 19, 121-131.

Vance, J., Wulf, G., Töllner, T., McNevin, N. H., \& Mercer, J. (2004). EMG activity as a function of the performers' focus of attention. Journal of Motor Behavior, 36, 450-459.

Vereijken, B., van Emmerik, R. E. A., Whiting, H. T. A., \& Newell, K. M. (1992). Free(z)ing degrees of freedom in skill acquisition. Journal of Motor Behavior, 24, 133-142.

Vickers, J. N. (1996). Visual control when aiming at a far target. Journal of Experimental Psychology: Human Perception and Performance, $22,342-354$.

Vickers, J. N. (2009). Advances in coupling perception and action: The quiet eye as a bidirectional link between gaze, attention and action. In: M. Raab, J. G. Johnson, \& H. R. Heekeren (Eds.), Progress in Brain Research (p. 279-288), Vol. 174, Mind and Motion: The bidirectional link between thought and action. The Netherlands: Elsevier.

Vine, S. J., Moore, S. J., \& Wilson, M. R. (2011). Quiet eye training facilitates competitive putting performance in elite golfers. Frontiers in Psychology, 2, 8. doi:10.3389/fpsyg.2011.00008

Vine, S. J., Moore, S. J., \& Wilson, M. R. (2015). Quiet eye training: The acquisition, refinement and resilient performance of targeting skills. European Journal of Sport Science, 14(Supplement 1), 235-242. doi:10.1080/17461391.2012.683815

Voss, S. C., \& Homzie, M. J. (1970). Choice as a value. Psychological Reports, 26, 912-914.

Wager, T. D., \& Altas, L. A. (2015). The neuroscience of placebo effects: Connecting context, learning and health. Nature Reviews Neuroscience, 16, 403-418.

Watkins, D. (1984). Students' perceptions of factors influencing tertiary learning. Higher Education Research and Development, 3, 33-50.

Watson, D. and Clark, L.A. (1999). The PANAS-X: Manual for the Positive and Negative Affect Schedule-Expanded Form. Retrieved September 29, 2015 from Iowa Research Online: http://ir.uiowa. edu/cgi/viewcontent.cgi?article $=1011 \&$ context=psychology pubs

Watson, D., Clark, L. A., \& Tellegen, A. (1988). Development and validation of brief measures of positive and negative affect: The PANAS Scales. Journal of Personality and Social Psychology, 54, 1063-1070.

White, R. W. (1959). Motivation reconsidered: The concept of competence. Psychological Review, 66, 297-333.

White, M. H., II, \& Sheldon, K. M. (2014). The contract year syndrome in the NBA and MLB: A classic undermining pattern. Motivation and Emotion, 38, 196-205.

Wilson, B. M., Mickes, L., Stolarz-Fantino, S., Evrard, M., \& Fantino, E. (2015). Increased false-memory susceptibility after mindfulness meditation Psychological Science OnlineFirst, published on September 4, 201. doi: 10.1177/0956797615593705

Wise, R. A. (2004). Dopamine, learning and motivation. Nature Reviews Neuroscience, 5, 1-12. 
Witt, J. K., Linkenauger, S. A., \& Proffitt, D. R. (2012). Get me out of this slump! Visual illusions improve sports performance. Psychological Science, 23, 397-399.

Witt, J. K., South, S. C., \& Sugovic, M. (2014). A perceiver's own abilities influence perception, even when observing others. Psychonomic Bulletin \& Review, 21, 384-389.

Wu, W. F. W., Porter, J. M., \& Brown, L. E. (2012). Effect of attentional focus strategies on peak force and performance in the standing long jump. Journal of Strength and Conditioning Research, 26, 1226-1231.

Wu, J., Srinivasan, R., Kaur, A., \& Cramer, S. C. (2014). Resting-state cortical connectivity predicts motor skill acquisition. NeuroImage, 91, 84-90.

Wulf, G. (2007a). Attention and motor skill learning. Champaign: Human Kinetics.

Wulf, G. (2007b). Self-controlled practice enhances motor learning: Implications for physiotherapy. Physiotherapy, 93, 96-101.

Wulf, G. (2013). Attentional focus and motor learning: A review of 15 years. International Review of Sport and Exercise Psychology, 6, $77-104$.

Wulf, G. (2016). Why did Tiger Woods shoot 82? A commentary on Toner and Moran (2015). Psychology of Sport and Exercise, 22, $337-338$

Wulf, G., \& Adams, N. (2014). Small choices can enhance balance learning. Human Movement Science, 38, 235-240.

Wulf, G., Chiviacowsky, S., Schiller, E., \& Ávila, L. T. (2010a). Frequent external-focus feedback enhances learning. Frontiers in Psychology, 1, 190. doi:10.3389/fpsyg.2010.00190

Wulf, G., Chiviacowsky, S., \& Cardozo, P. (2014a). Additive benefits of autonomy support and enhanced expectancies for motor learning. Human Movement Science, 37, 12-20.

Wulf, G., Chiviacowsky, S., \& Drews, R. (2015). External focus and autonomy support: Two important factors in motor learning have additive benefits. Human Movement Science, 40, 176-184.

Wulf, G., Chiviacowsky, S., \& Lewthwaite, R. (2010b). Normative feedback effects on the learning of a timing task. Research Quarterly for Exercise and Sport, 81, 425-431.

Wulf, G., Chiviacowsky, S., \& Lewthwaite, R. (2012). Altering mindset can enhance motor learning in older adults. Psychology and Aging, 27, 14-21.

Wulf, G., Clauss, A., Shea, C. H., \& Whitacre, C. (2001a). Benefits of self-control in dyad practice. Research Quarterly for Exercise and Sport, 72, 299-303.

Wulf, G., \& Dufek, J. S. (2009). Increased jump height with an external focus due to enhanced lower extremity joint kinetics. Journal of Motor Behavior, 41, 401-409.

Wulf, G., Dufek, J. S., Lozano, L., \& Pettigrew, C. (2010c). Increased jump height and reduced EMG activity with an external focus of attention. Human Movement Science, 29, 440-448.

Wulf, G., Freitas, H. E., \& Tandy, R. D. (2014b). Choosing to exercise more: Small choices can increase exercise engagement. Psychology of Sport and Exercise, 15, 268-271.

Wulf, G., Höß, M., \& Prinz, W. (1998). Instructions for motor learning: Differential effects of internal versus external focus of attention. Journal of Motor Behavior, 30, 169-179.
Wulf, G., Landers, M., Lewthwaite, R., \& Töllner, T. (2009). External focus instructions reduce postural instability in individuals with Parkinson disease. Physical Therapy, 89, 162-168.

Wulf, G., \& Lewthwaite, R. (2009). Conceptions of ability affect motor learning. Journal of Motor Behavior, 41, 461-467.

Wulf, G., \& Lewthwaite, R. (2010). Effortless motor learning? An external focus of attention enhances movement effectiveness and efficiency. In B. Bruya (Ed.), Effortless Attention: A New Perspective in Attention and Action (pp. 75-101). Cambridge: MIT Press.

Wulf, G., Lewthwaite, R., \& Hooyman, A. (2013). Can ability conceptualizations alter the impact of social comparison in motor learning? Journal of Motor Learning and Development, 1, 20-30.

Wulf, G., McNevin, N. H., \& Shea, C. H. (2001b). The automaticity of complex motor skill learning as a function of attentional focus. Quarterly Journal of Experimental Psychology, 54A, 1143-1154.

Wulf, G., \& Prinz, W. (2001). Directing attention to movement effects enhances learning: A review. Psychonomic Bulletin \& Review, 8, 648-660.

Wulf, G., Raupach, M., \& Pfeiffer, F. (2005). Self-controlled observational practice enhances learning. Research Quarterly for Exercise and Sport, 76, 107-111.

Wulf, G., \& Schmidt, R. A. (1997). Variability of practice and implicit motor learning. Journal of Experimental Psychology: Learning, Memory, and Cognition, 23, 987-1006.

Wulf, G., Shea, C. H., \& Park, J. H. (2001c). Attention and motor learning: Preferences for and advantages of an external focus. Research Quarterly for Exercise and Sport, 72, 335-344.

Wulf, G., \& Su, J. (2007). External focus of attention enhances golf shot accuracy in beginners and experts. Research Quarterly for Exercise and Sport, 78, 384-389.

Wulf, G., \& Toole, T. (1999). Physical assistance devices in complex motor skill learning: Benefits of a self-controlled practice schedule. Research Quarterly for Exercise and Sport, 70, 265-272.

Wulf, G., Weigelt, M., Poulter, D. R., \& McNevin, N. H. (2003). Attentional focus on supra-postural tasks affects balance learning. Quarterly Journal of Experimental Psychology, 56, 1191-1211.

Wulf, G., Zachry, T., Granados, C., \& Dufek, J. S. (2007). Increases in jump-and-reach height through an external focus of attention. International Journal of Sport Science and Coaching, 2, 275-282.

Yagishita, S., Hayashi-Takagi, A., Ellis-Davies, G. C. R., Urakubo, H., Ishii, S., \& Kasai, H. (2014). A critical time window for dopamine actions on the structural plasticity of dendritic spines. Science, 345, 1606-1620.

Yin, H. H., Ostlund, S. B., \& Balleine, B. W. (2008). Reward-guided learning beyond dopamine in the nucleus accumbens: The integrative functions of cortico-basal ganglia networks. European Journal of Neuroscience, 28, 1437-1448.

Zachry, T., Wulf, G., Mercer, J., \& Bezodis, N. (2005). Increased movement accuracy and reduced EMG activity as the result of adopting an external focus of attention. Brain Research Bulletin, 67, 304-309.

Zahodne, L. B., Nowinski, C. J., Gershon, R. C., \& Manly, J. J. (2015). Self-efficacy buffers the relationship between educational disadvantage and executive functioning. Journal of the International Neuropsychological Society, 21, 297-304.

Zarghami, M., Saemi, E., \& Fathi, I. (2012). External focus of attention enhances discus throwing performance. Kinesiology, 44, 47-51. 